A molecular dynamics study of the role of molecular water on the structure and mechanics of amorphous geopolymer binders

Mohammad Rafat Sadat', Stefan Bringuier, Abu Asaduzzaman, Krishna Muralidharan, and Lianyang Zhang

Citation: J. Chem. Phys. 145, 134706 (2016); doi: 10.1063/1.4964301

View online: http://dx.doi.org/10.1063/1.4964301

View Table of Contents: http://aip.scitation.org/toc/jcp/145/13

Published by the American Institute of Physics 


\title{
A molecular dynamics study of the role of molecular water on the structure and mechanics of amorphous geopolymer binders
}

\author{
Mohammad Rafat Sadat, ${ }^{1, a)}$ Stefan Bringuier, ${ }^{2}$ Abu Asaduzzaman, ${ }^{2}$ Krishna Muralidharan, ${ }^{2}$ \\ and Lianyang Zhang ${ }^{1}$ \\ ${ }^{1}$ Department of Civil Engineering and Engineering Mechanics, University of Arizona, \\ Tucson, Arizona 85721, USA \\ ${ }^{2}$ Department of Materials Science and Engineering, University of Arizona, Tucson, Arizona 85721, USA
}

(Received 13 July 2016; accepted 22 September 2016; published online 7 October 2016)

\begin{abstract}
In this paper, molecular dynamics simulations are used to study the effect of molecular water and composition $(\mathrm{Si} / \mathrm{Al}$ ratio) on the structure and mechanical properties of fully polymerized amorphous sodium aluminosilicate geopolymer binders. The X-ray pair distribution function for the simulated geopolymer binder phase showed good agreement with the experimentally determined structure in terms of bond lengths of the various atomic pairs. The elastic constants and ultimate tensile strength of the geopolymer binders were calculated as a function of water content and $\mathrm{Si} / \mathrm{Al}$ ratio; while increasing the $\mathrm{Si} / \mathrm{Al}$ ratio from one to three led to an increase in the respective values of the elastic stiffness and tensile strength, for a given $\mathrm{Si} / \mathrm{Al}$ ratio, increasing the water content decreased the stiffness and strength of the binder phase. An atomic-scale analysis showed a direct correlation between water content and diffusion of alkali ions, resulting in the weakening of the $\mathrm{AlO}_{4}$ tetrahedral structure due to the migration of charge balancing alkali ions away from the tetrahedra, ultimately leading to failure. In the presence of water molecules, the diffusion behavior of alkali cations was found to be particularly anomalous, showing dynamic heterogeneity. This paper, for the first time, proves the efficacy of atomistic simulations for understanding the effect of water in geopolymer binders and can thus serve as a useful design tool for optimizing composition of geopolymers with improved mechanical properties. Published by AIP Publishing. [http://dx.doi.org/10.1063/1.4964301]
\end{abstract}

\section{INTRODUCTION}

A geopolymer is a novel cementitious material formed by the alkali activation of aluminosilicate source materials such as fly ash, metakaolin, blast furnace slag, and mine tailings. ${ }^{1-4}$ The molecular structure of a geopolymer has been widely investigated using NMR spectroscopy ${ }^{5-10}$ and the results show that geopolymers consist of rings and chains made of interconnected $\mathrm{Si}$ and $\mathrm{Al}$ tetrahedra crosslinked together to form a 3-D network structure. Alkali cations such as $\mathrm{Na}^{+}, \mathrm{K}^{+}$, or $\mathrm{Cs}^{+}$are essential to compensate the negative charge associated with the $\mathrm{AlO}_{4}$ tetrahedra, but are not considered to be part of the ring structures that comprise the geopolymer network. ${ }^{7,10}$ Water is necessary for the synthesis and polymerization of geopolymer and remains distributed in the final structure. ${ }^{11}$ Typically, the precursor material is incompletely polymerized, leading to regions of unreacted precursor phase in addition to the fully polymerized geopolymer binder phase within the geopolymer composite.

Neutron pair distribution function (PDF) study conducted by White et al. ${ }^{12}$ has shown that the majority of water in metakaolin-based geopolymer is lost at a temperature below $200{ }^{\circ} \mathrm{C}$ and only a small amount $(\sim 5 \%)$ is present in nanopores within the binder phase and as terminal $-\mathrm{OH}$ in the framework of $\mathrm{Si}-\mathrm{Al}$, as also suggested by Duxson et al. ${ }^{11}$

\footnotetext{
a) Author to whom correspondence should be addressed. Electronic mail: msadat@email.arizona.edu.
}

For fly ash-based geopolymers, it has been observed that the water remaining within the geopolymer up to a temperature of $1050{ }^{\circ} \mathrm{C}$ is in the non-disassociated molecular form and constitutes about $11 \mathrm{wt} . \%$ of the total system. ${ }^{13}$

While it is clear that water is an integral part of the final geopolymer structure and remains within the geopolymer binder permanently, so far, there has been no systematic effort towards understanding and characterizing the role of residual water on the ensuing geopolymer structure and mechanical properties. Further, geopolymers are prone to efflorescence leading to decrease in geopolymer mechanical integrity, which arises due to the leaching of alkali ions when they are in contact with water. ${ }^{14,15}$ However, the mechanisms governing the efflorescence-mechanical property interplay is not well understood. Thus to achieve a fundamental understanding of the structure-mechanical property relations of geopolymers, in this work, we have carried out molecular dynamics (MD) simulations that examine the role of the alkali ions and residual molecular water (trapped within the nano pores of the geopolymer binder phase) on the mechanical properties of geopolymers. Equally importantly, we carry out this study as a function of composition ( $\mathrm{Si} / \mathrm{Al}$ ratio) in addition to as a function of water content. We restrict our studies to Na based geopolymers, such that $\mathrm{Na} / \mathrm{Al}$ ratio is always maintained at one to ensure charge balance. It is worthwhile to point out that in a previous study, ${ }^{16}$ we used $\mathrm{Na}$-aluminosilicate (NAS) glasses as a proxy in order to understand the effect of $\mathrm{Si} / \mathrm{Al}$ ratio on the mechanical properties of a nominally 
fully dense geopolymer binder phase devoid of water and nanopores. The current study represents a follow up in which the effect of nano-voids and molecular water is explicitly included in order to observe the interplay between the binder porosity, the presence of water, and the variation in the Si/Al ratio on the structure-mechanical property relations of the geopolymer binder phase. Since our focus is on enabling a fundamental, atomic-scale characterization of the above interplay, we focus our efforts solely on the fully polymerized binder phase, and do not include the unreacted precursor material in our study. However, lessons learned from this work will serve as an important stepping-stone for developing multiscale modeling methods for incorporating the meso- and macro-scale precursor phases in conjunction with the binder phase in order to comprehensively and holistically describe geopolymer composite.

\section{BACKGROUND}

Geopolymers are considered a binder analogous to calcium silicate hydrate (CSH) gel phase in ordinary Portland cement hydrates which binds or connects the precursor materials forming a composite matrix. Most geopolymers consist of unreacted precursor materials within them, making it very difficult to isolate and study the intrinsic binder phase. Kriven et al. ${ }^{17}$ made the first attempt to study the fully reacted binder phase of geopolymers and correlated the microstructure with the underlying chemistry. The microstructure of fully reacted geopolymer was found to be consisting of nanoparticulates of $20 \mathrm{~nm}$ diameter separated by nano voids of the order of $10 \mathrm{~nm}$ as observed in the transmission electron microscope (TEM) images. In a different study made by Kriven et al. ${ }^{18}$ the average pore radius of an intrinsic geopolymer was found to be $3.4 \mathrm{~nm}$ when natural metakaolin was used as source material and it reduced to $0.8 \mathrm{~nm}$ when pure synthetic aluminosilicate metakaolin was chosen instead.

Although considerable amount of modeling work has been undertaken to understand the atomic level structure and mechanical property interplay of $\mathrm{CSH}$ gel, ${ }^{19-25}$ a very limited number of studies have been carried out to examine the intrinsic geopolymer binder phase. White $\mathrm{et} \mathrm{al.} .^{26}$ used density functional theory (DFT) based coarse grained Monte-Carlo (CGMC) simulation technique to understand the molecular mechanisms responsible for the structural changes that occur during geopolymerization using metakaolin as source materials. However, to the best of our knowledge there is still a dearth of information correlating the structure and mechanical properties of geopolymers in terms of their primary constituents namely alkali aluminosilicates and molecular water. In this context, this work will provide a fundamental understanding of the structure-mechanical property relations of hydrated geopolymers.

\section{METHODOLOGY OF MD SIMULATION}

\section{A. Interatomic potential}

In MD simulations, choosing an appropriate interatomic potential is required to enable the ability to model the atomic scale mechanisms governing the mechanical response of materials. In this work, we chose potentials that were earlier validated for compositionally similar systems such as zeolites and metakaolin. The interaction between molecular water and geopolymer network atoms was based on previous work that examined water-zeolite systems, ${ }^{27,28}$ in addition to applications for examining the dehydroxylation mechanism of kaolinite to metakaolin. ${ }^{29}$ Here we denote the structural or the network forming oxygen as $\mathrm{O}_{\mathrm{s}}$, the water oxygen as $\mathrm{O}_{\mathrm{w}}$, and the hydrogen atoms comprising the water molecules as $\mathrm{H}_{\mathrm{w}}$. The functional form of the short-range interaction between $\mathrm{M}-\mathrm{O}_{\mathrm{s}}(\mathrm{M}$ $=\mathrm{Si}, \mathrm{Al}, \mathrm{Na}), \mathrm{O}_{\mathrm{s}}-\mathrm{O}_{\mathrm{s}}$, and $\mathrm{O}_{\mathrm{s}}-\mathrm{H}_{\mathrm{w}}$ is given by the Buckingham potential

$$
V(r)=A \exp (-r / \rho)-C / r^{6}
$$

which consists of a Born-Meyer repulsion term and an attraction term. $A, \rho$, and $C$ are parameters given in Table I and $r$ is the distance between atomic pairs. Further, to

TABLE I. Interatomic potential parameters ${ }^{35}$ used for simulating the GPxW systems.

\begin{tabular}{lccc}
\hline \hline Atoms & Charge & Atoms & Charge \\
\hline $\mathrm{Si}$ & +2.4 & $\mathrm{O}_{\mathrm{s}}{ }^{\mathrm{a}}$ & -1.2 \\
$\mathrm{Al}$ & +1.8 & $\mathrm{O}_{\mathrm{w}}{ }^{\mathrm{b}}$ & -0.82 \\
$\mathrm{Na}$ & +0.6 & $\mathrm{H}_{\mathrm{w}}{ }^{\mathrm{c}}$ & +0.41 \\
\hline
\end{tabular}

2-body Buckingham potential parameters

\begin{tabular}{lclc}
\hline Atomic pair & $A(\mathrm{eV})$ & $\rho(\AA)$ & $C\left(\mathrm{eV} \AA^{6}\right)$ \\
\hline $\mathrm{Si}-\mathrm{O}_{\mathrm{s}}$ & 13702.9050 & 0.193817 & 54.681 \\
$\mathrm{Al}-\mathrm{O}_{\mathrm{s}}$ & 12201.4170 & 0.195628 & 31.997 \\
$\mathrm{Na}-\mathrm{O}_{\mathrm{s}}$ & 2755.0323 & 0.258583 & 33.831 \\
$\mathrm{Na}-\mathrm{O}_{\mathrm{w}}$ & 2616.2137 & 0.258583 & 33.831 \\
$\mathrm{O}_{\mathrm{s}}-\mathrm{O}_{\mathrm{s}}$ & 2029.2233 & 0.343645 & 192.58 \\
$\mathrm{O}_{\mathrm{s}}-\mathrm{H}_{\mathrm{w}}$ & 100.0 & 0.25 & 0.0 \\
\hline
\end{tabular}

2-body Lennard-Jones potential parameters

\begin{tabular}{lcc}
\hline Atomic pair & $\varepsilon(\mathrm{eV})$ & $\sigma(\AA)$ \\
\hline $\mathrm{O}_{\mathrm{s}}-\mathrm{O}_{\mathrm{w}}$ & 0.024309 & 2.4952 \\
$\mathrm{O}_{\mathrm{w}}-\mathrm{O}_{\mathrm{w}}$ & 0.006735 & 3.1690 \\
\hline
\end{tabular}

2-body composite potential parameters

\begin{tabular}{lccc}
\hline Atomic pair & $A(\mathrm{eV})$ & $\rho(\AA)$ & $\sigma\left(\mathrm{eV}^{-12} \AA\right)$ \\
\hline $\mathrm{Si}-\mathrm{O}_{\mathrm{w}}$ & 0.5883 & 2.7561 & 1.225 \\
$\mathrm{Al}-\mathrm{O}_{\mathrm{w}}$ & 4.7788 & 2.5235 & 1.223 \\
\hline
\end{tabular}

Bond stretching parameters

\begin{tabular}{lcc}
\hline Atomic pair & $k_{a}\left(\mathrm{eV} / \AA^{2}\right)$ & $r_{0}(\AA)$ \\
\hline $\mathrm{O}_{\mathrm{w}}-\mathrm{H}_{\mathrm{w}}$ & 45.93 & 1.012 \\
\hline & &
\end{tabular}

Angle bending parameters

\begin{tabular}{lcc}
\hline Triplet & $k_{b}\left(\mathrm{eV} / \mathrm{rad}^{2}\right)$ & $\theta_{0}$ \\
\hline $\mathrm{H}_{\mathrm{w}}-\mathrm{O}_{\mathrm{w}}-\mathrm{H}_{\mathrm{w}}$ & 3.29136 & 113.24
\end{tabular}

${ }^{\text {a Structural oxygen. }}$

${ }^{\mathrm{b}}$ Water oxygen.

${ }^{\mathrm{c}}$ Water hydrogen. 
avoid unphysical interactions between neighboring oxygen atoms at short distances, we also added a repulsive term $\frac{B}{r^{n}}$ (where $B=100 \mathrm{eV} \AA^{8}, n=8$ ) to the Buckingham potential. Similar modifications to the Buckingham term have been done previously on many occasions. ${ }^{30-34}$

For $\mathrm{Si}-\mathrm{O}_{\mathrm{w}}$ and $\mathrm{Al}-\mathrm{O}_{\mathrm{w}}$ interactions, functional forms [Eq. (2)] as developed by Sperinck $^{35}$ were used, with the respective parameters given in Table I,

$$
V(r)=A \exp (-r / \rho)+(\sigma / r)^{12} .
$$

Additionally, based on Sperinck, ${ }^{35}$ the interactions between $\mathrm{O}_{\mathrm{s}}$ and $\mathrm{O}_{\mathrm{w}}$ as well as $\mathrm{O}_{\mathrm{w}}-\mathrm{O}_{\mathrm{w}}$ were modeled using a Lennard-Jones potential [Eq. (3)], while a SPC/Fw force field ${ }^{36}$ modified by Sperinck ${ }^{35}$ was employed to model $\mathrm{H}_{\mathrm{w}}-\mathrm{O}_{\mathrm{w}}$ interactions within a water molecule. Here, the SPC/Fw model was restricted to only including the bond stretching and an angle bending term as given below in Eq. (4a) and Eq. (4b), respectively,

$$
\begin{gathered}
V(r)=4 \varepsilon\left[\left(\frac{\sigma}{r}\right)^{12}-\left(\frac{\sigma}{r}\right)^{6}\right], \\
V(r)=\frac{1}{2} k_{a}\left(r-r_{0}\right)^{2}, \\
V(r)=\frac{1}{2} k_{b}\left(\theta-\theta_{0}\right)^{2} .
\end{gathered}
$$

Here $r_{0}$ and $\theta_{0}$ are the equilibrium bond length and bond angle, respectively, while $k_{a}$ and $k_{b}$ are the force constants. $r$ and $\theta$ are the distance between atomic pairs and bond angle between two hydrogen $\left(\mathrm{H}_{\mathrm{w}}\right)$ and the central oxygen $\left(\mathrm{O}_{\mathrm{w}}\right)$.

For long range Coulombic interactions, a particle particleparticle particle-mesh (pppm) solver ${ }^{37}$ was used with a cutoff of $12 \AA$ for fast and accurate convergence of real space and reciprocal space terms. Similar cutoff was used for short-range interactions as well. The complete list of the potential parameters for the different atomic pairs and the partial charges is listed in Table I. Note that unlike for the water molecules, there are no corresponding intramolecular bond-terms ([Eq. (4a)] and [Eq. (4b)]) for the $\mathrm{M}-\mathrm{O}_{\mathrm{s}}$ interactions, and the Buckingham potential [Eq. (1)] is solely used for describing the non-Coulombic part of their interactions.

\section{B. Structure generation and details of MD simulations}

In order to examine the structure-composition-mechanical property relations of geopolymers, the MD simulation package LAMMPS $^{38}$ was used. In this regard, as a first step, geopolymer structures with different $\mathrm{Si} / \mathrm{Al}$ ratios (1-3) as well as different water contents (0-6.6 wt. \%) were simulated. To construct the geopolymer structures with different $\mathrm{Si} / \mathrm{Al}$ ratios, one of the three following monomers (building blocks), namely poly-sialate $(\mathrm{Si} / \mathrm{Al}=1)$, poly-sialate-siloxo $(\mathrm{Si} / \mathrm{Al}$ $=2)$, and poly-sialate-disilixo $(\mathrm{Si} / \mathrm{Al}=3)$ as originally proposed by Davidovits ${ }^{1}$ was selected in conjunction with the appropriate number of $\mathrm{Na}$ atoms and water molecules (see Table II for a full list of compositions). For generating the geopolymer structures, the monomers, the $\mathrm{Na}$ atoms, and the water molecules were initially assigned random positions, with each unit separated by at least $2 \AA$, within a cubic box as shown in Figure 1(a) (generated using the visualization software OVITO $^{39}$ ) utilizing the software Packmol. ${ }^{40}$ Periodic boundary conditions were imposed in all three directions and the systems were subjected to constrained NVE ensemble runs, where the maximum displacement of atoms was restricted to $0.005 \AA$ per time step. This was followed by respective NVT runs at $300 \mathrm{~K}$ and a subsequent heating/cooling cycle, where the temperature of the systems was raised up to $4000 \mathrm{~K}$ to remove any memory effects $^{30,41,42}$ and then cooled down at a cooling rate of $5 \mathrm{~K} / \mathrm{ps}$ to $300 \mathrm{~K}$. Further, raising the temperature to $4000 \mathrm{~K}$ also ensured highly connected network structures in all systems. As a final step, the systems were further equilibrated for $200 \mathrm{ps}$ under NPT (=0 bar) conditions, followed by an NVT run at $300 \mathrm{~K}$ for $300 \mathrm{ps}$, leading to well-equilibrated structures. For all systems, six different initial configurations were generated to provide better statistical averaging, while the initial velocities of the atoms were prescribed based on a Gaussian distribution.

A snapshot of an equilibrated structure is shown in

\begin{tabular}{|c|c|c|c|c|c|c|c|c|}
\hline Name & $\mathrm{Si} / \mathrm{Al}$ ratio & $\mathrm{SiO}_{2}($ wt. \%) & $\mathrm{Al}_{2} \mathrm{O}_{3}$ (wt. \%) & $\mathrm{Na}_{2} \mathrm{O}$ (wt. \%) & $\mathrm{H}_{2} \mathrm{O}$ (wt. \%) & $\begin{array}{l}\text { Total atoms in } \\
\text { simulation cell }\end{array}$ & $\begin{array}{l}\text { Skeletal density } \\
\quad\left(\mathrm{gm} / \mathrm{cm}^{3}\right)\end{array}$ & $\begin{array}{c}\text { Gel density } \\
\left(\mathrm{gm} / \mathrm{cm}^{3}\right)\end{array}$ \\
\hline GBP1 & 1 & 42.30 & 35.89 & 21.81 & 0.00 & 39998 & 2.51 & 2.51 \\
\hline $\mathrm{GP}_{1} \mathrm{~W}_{\mathrm{i}}$ & 1 & 41.20 & 34.96 & 21.24 & 2.59 & 43598 & 2.01 & 2.05 \\
\hline GP1W & 1 & 40.33 & 34.22 & 20.80 & 4.65 & 46598 & 1.98 & 2.06 \\
\hline GP1W & 1 & 39.50 & 33.51 & 20.36 & 6.63 & 49598 & 1.95 & 2.05 \\
\hline GBP2 & 2 & 59.45 & 25.22 & 15.33 & 0.00 & 40000 & 2.45 & 2.45 \\
\hline $\mathrm{GP}_{2} \mathrm{~W}_{\mathrm{i}}$ & 2 & 57.90 & 24.57 & 14.93 & 2.60 & 43600 & 1.97 & 2.00 \\
\hline GP2W $W_{\mathrm{ii}}$ & 2 & 56.68 & 24.04 & 14.61 & 4.67 & 46600 & 1.95 & 2.01 \\
\hline GP2W $W_{\text {iii }}$ & 2 & 55.50 & 23.54 & 14.31 & 6.65 & 49600 & 1.92 & 2.03 \\
\hline GBP3 & 3 & 68.74 & 19.44 & 11.81 & 0.00 & 40001 & 2.41 & 2.41 \\
\hline GP3W & 3 & 66.95 & 18.94 & 11.51 & 2.61 & 43601 & 1.95 & 1.98 \\
\hline GP3W & 3 & 65.53 & 18.53 & 11.26 & 4.68 & 46601 & 1.92 & 1.99 \\
\hline GP3W & 3 & 64.16 & 18.15 & 11.03 & 6.66 & 49601 & 1.90 & 2.00 \\
\hline
\end{tabular}
Figure 1 (b) for a $\mathrm{Si} / \mathrm{Al}$ ratio of 2 containing $2.6 \mathrm{wt}$. \% water.

TABLE II. A tabulation of the composition of the various GPxW systems studied in this work (for convenience the composition is expressed in terms of SiO 2 , $\mathrm{Al}_{2} \mathrm{O}_{3}$, and $\mathrm{Na}_{2} \mathrm{O}$ units, while the simulated systems primarily consist of $\mathrm{SiO}_{4}$ and $\mathrm{AlO}_{4}$ tetrahedra). 


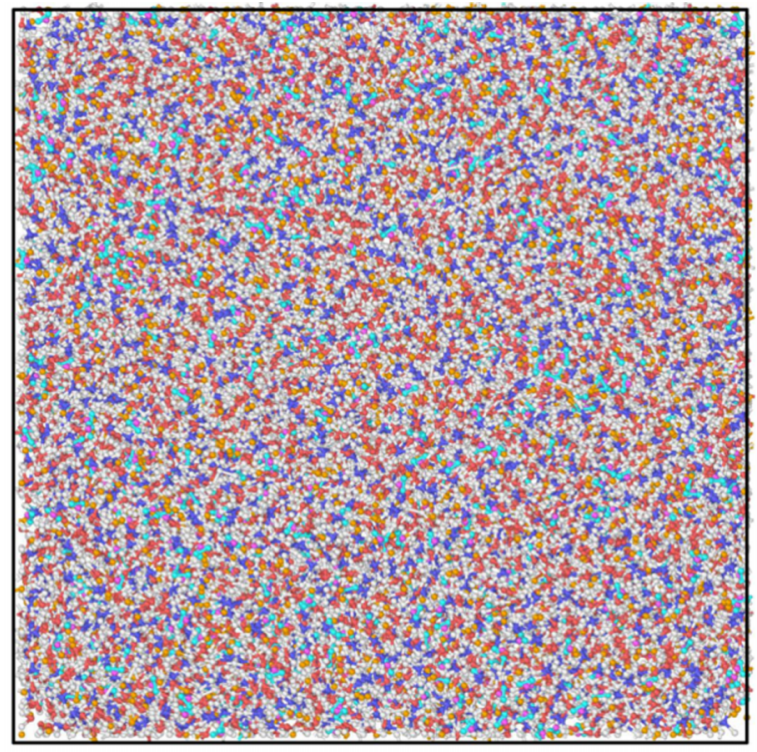

(a)

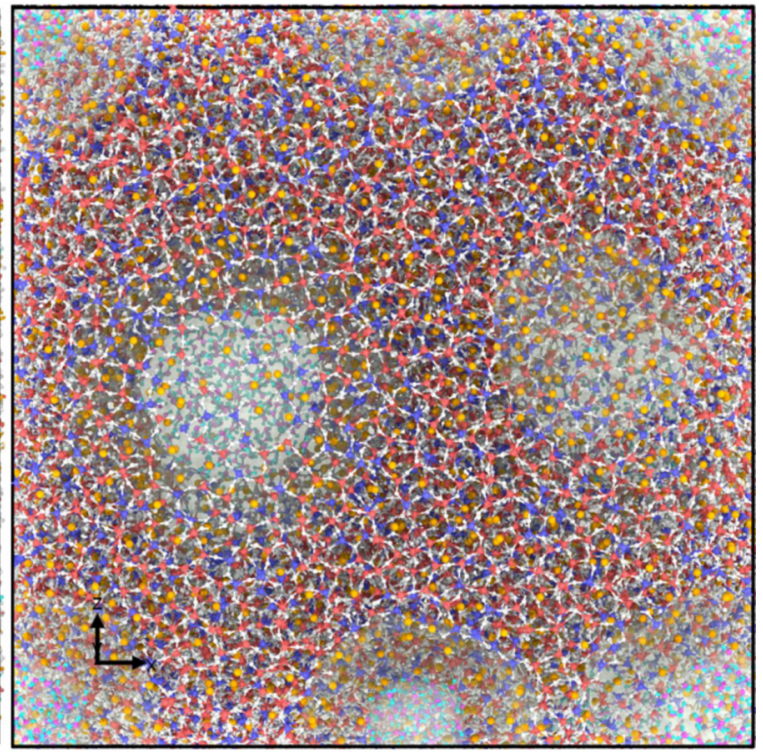

(b)

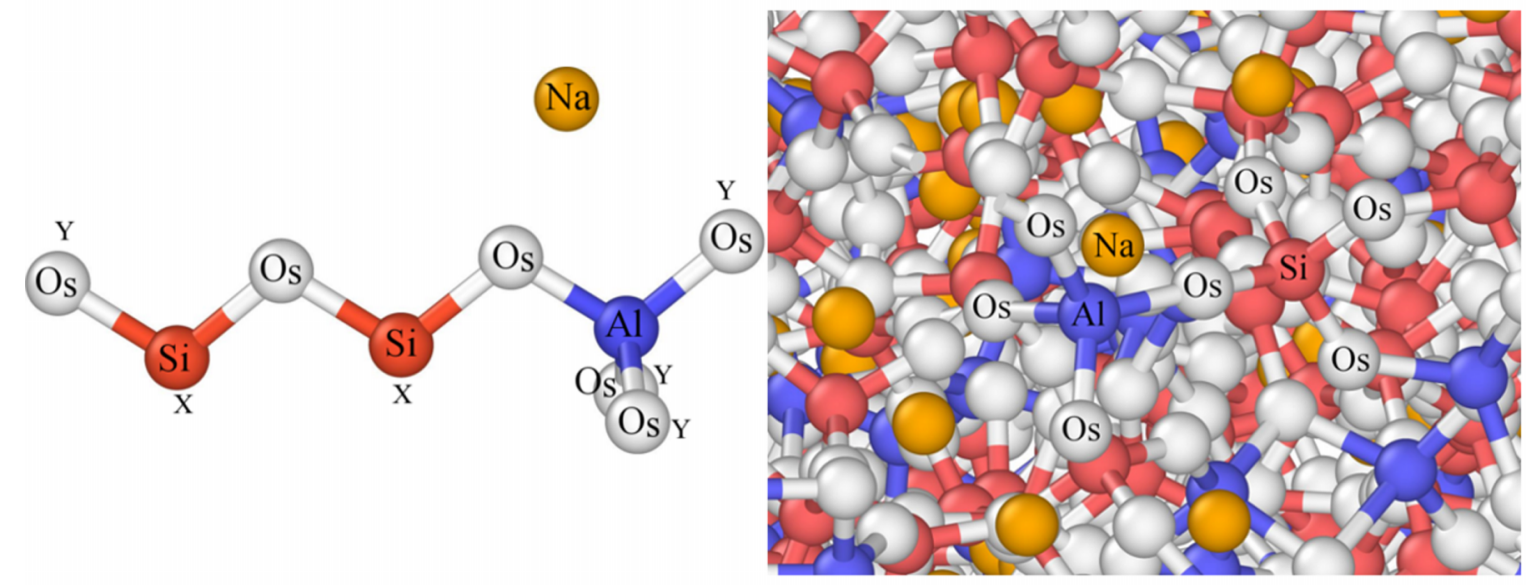

(c)

(d)

FIG. 1. (a) Planar (zx) view of the initial configuration of $\mathrm{GP}_{2} \mathrm{~W}_{\mathrm{i}}$; red $=\mathrm{Si}$, blue $=\mathrm{Al}$, orange $=\mathrm{Na}$, white $=\mathrm{O}$, magenta $=\mathrm{O}_{\mathrm{w}}($ water oxygen $)$, cyan $=\mathrm{H}_{\mathrm{w}}($ water hydrogen). (b) Structure of the geopolymer after MD equilibration. The voids and water clusters within the geopolymer are highlighted. (c) Poly-sialate-silixo monomer (i.e., the building blocks), which was used to construct this model. " $x$ " and " $y$ " represent sites that are susceptible to polymerization. (d) A zoomed in image of the geopolymer structure in (b) illustrating the network connectivity of $\mathrm{Si}$ and $\mathrm{Al}$ tetrahedra.

In this case, the building blocks were the charge neutral polysialate-siloxo $(\mathrm{Si} / \mathrm{Al}=2)$ monomers as shown in Figure 1 $(\mathrm{c})$. The " $x$ " and " $y$ " labels in Figure 1(c) represent reactive sites that enable the formation of the 3-D network structure. Figure 1(d) shows a zoomed-in version of Figure 1(b) and depicts the 3-D geopolymer network consisting of the $\mathrm{Si}$ and the $\mathrm{Al}$ tetrahedra. As noted earlier, the $\mathrm{Na}$ atoms are not part of the network structure though their presence is necessary to ensure charge balance, leading to them being loosely bound to the $\mathrm{Al}$ tetrahedra. As evident from the above figures (i.e., Figures 1(a)-1(d)), while we started with individual monomers, the imposed MD conditions led to the formation of a 3-D connected network of Si and Al tetrahedra, as also observed experimentally. ${ }^{7}$ This further confirms the ability of the selected interatomic potentials to correctly model such systems.

In water containing systems, the water molecules formed nano droplets, within nano-voids, also consistent with experimental observations of the geopolymer binder matrix. ${ }^{11,12}$ To study the effect of water, the water molecules were removed from the nano voids and the structure was further equilibrated at $300 \mathrm{~K}$ and zero bar. For comparison, fully compacted geopolymer binders ("Geopolymer Binder Phase" or "GBP") without the presence of any water or voids were simulated as well; note that the mechanical properties of the fully compacted GBP structures were examined by us in an earlier published work. ${ }^{16}$ For convenience, in this work, we refer to the fully compacted geopolymer binder phase as GBP while the other systems are defined in Table II. In Table II, GBP1, GBP2, and GBP3 refer to the fully compacted GBP with $\mathrm{Si} / \mathrm{Al}$ ratios equaling 1,2 , and 3 , respectively, while any "GPxW $(\mathrm{x}=1,2,3)$ " system corresponds to a non-compacted geopolymer containing nano-voids and water. Here, "W" refers to the hydrated geopolymer phase. Further, the roman numerals (i, ii, iiii) that follow "W" refer to differing water content. While not explicitly noted in Table II, 


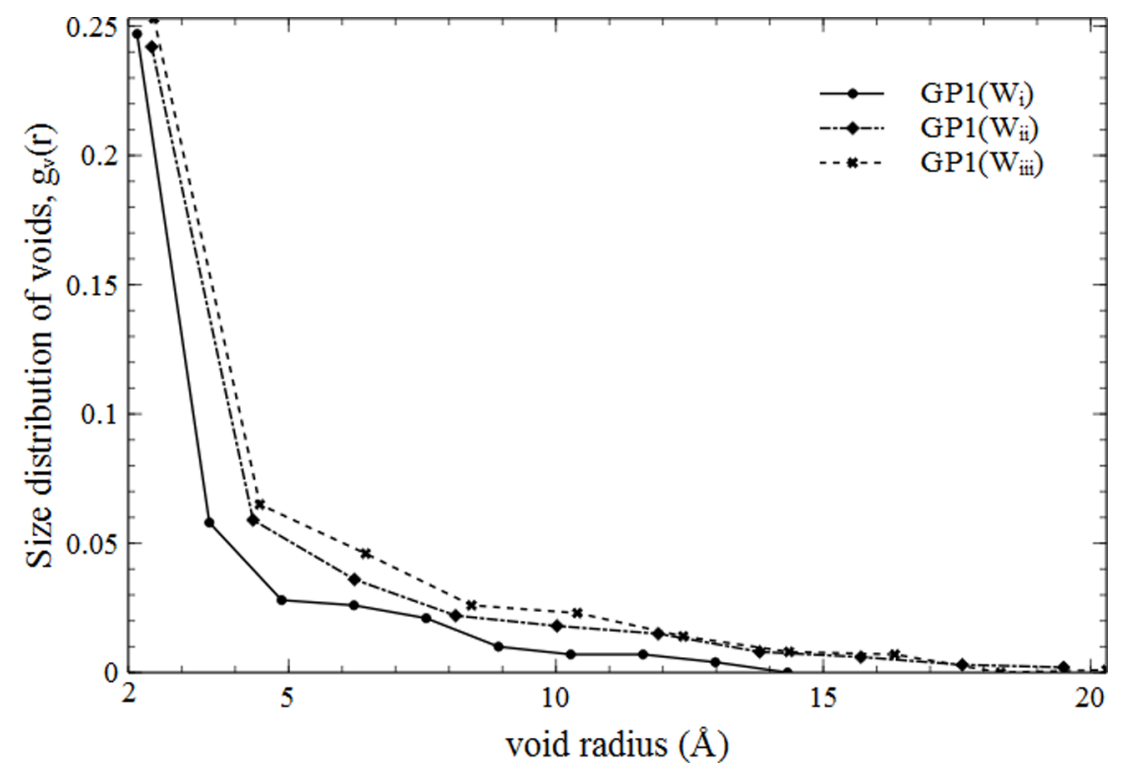

FIG. 2. Void size distribution of GP1(W) structures. $g_{v}(r)$ denotes the probability of finding a void of radius $r$. the "dehydrated" geopolymer systems are simply referred to as "GPx(W)." They were formed by removing the water molecules from the GPxW systems and then equilibrated at NPT conditions. Interestingly, there was minimal change in the skeletal density as well as the void size distribution for every pair of $\operatorname{GPx}(\mathrm{W})$ and GPxW systems. The reported skeletal density in Table II denotes the geopolymer matrix density while the gel density takes into account the presence of water. For a given $\mathrm{Si} / \mathrm{Al}$ ratio, increasing the water content decreases the skeletal density due to the increase in the nanoscale void population.

The void size distribution of the different $\operatorname{GPx}(\mathrm{W})$ structures was calculated using the RINGS code. ${ }^{43}$ Specifically, RINGS provides a pair correlation function $g_{v}(r)$, which is directly related to the probability distribution of the different void-sizes in the material. Figure 2 shows the void size distribution of a representative structure namely GP1(W). It can be seen that the void size increases with increasing water content. Similar trends in void size distributions were observed for other $\operatorname{GPx}(\mathrm{W})$ structures as well.

\section{RESULTS AND DISCUSSION}

\section{A. Validation of MD model with X-ray pair distribution function (PDF)}

Neutron and X-ray pair distribution functions (PDFs) have been widely used for validating disordered and amorphous materials simulated with $\mathrm{MD}^{19,20,44}$ and have also been employed for characterizing geopolymers. ${ }^{12,45-48}$ In MD simulations, the static neutron and X-ray structure factors $\mathrm{S}(\mathrm{Q})$ can be computed, from which the simulated $\mathrm{X}$-ray PDFs are obtained. In this work, we obtained the X-ray PDF of the simulated geopolymer structures using the RINGS code ${ }^{43}$ and compared with the experimentally determined X-ray PDF of a hardened geopolymer sample made from metakaolin by White et al. ${ }^{49}$ As shown in Figure 3, good agreement between

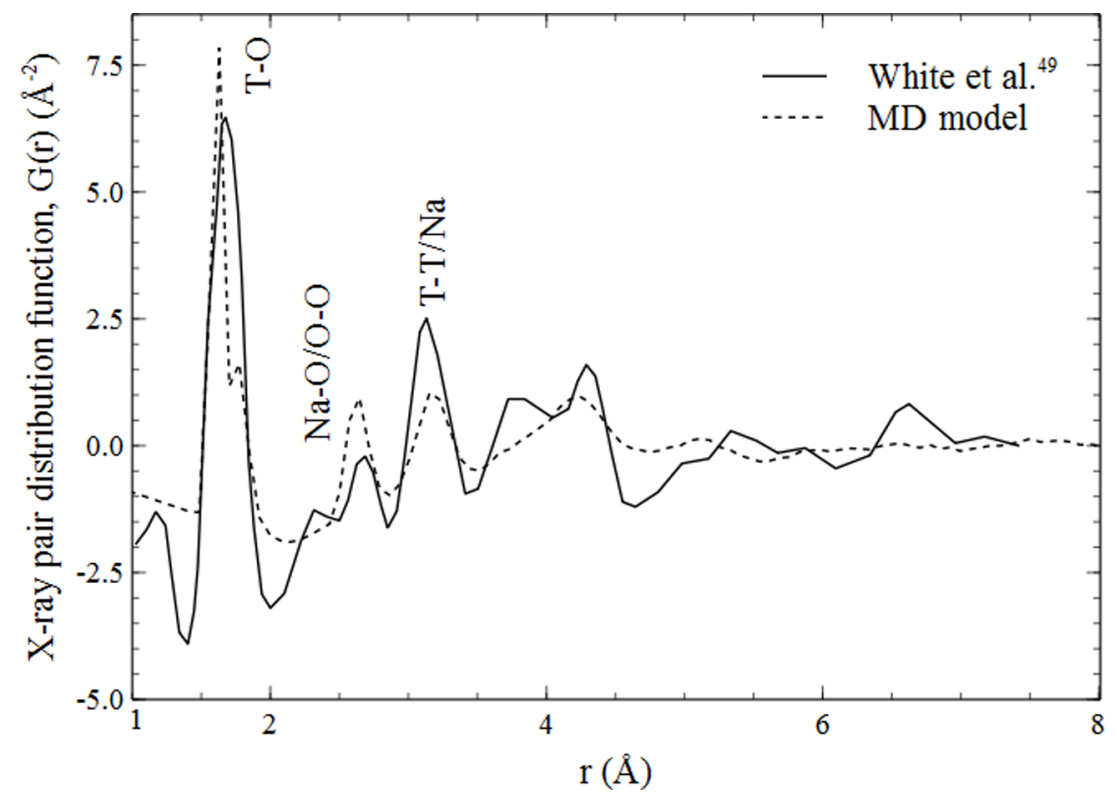

FIG. 3. Simulated X-ray PDF of the GBP2 geopolymer in comparison with an experimental X-ray PDF of a hardened metakaolin-based geopolymer synthesized by White et al. ${ }^{49} \mathrm{~T}$ denotes Si or Al. 


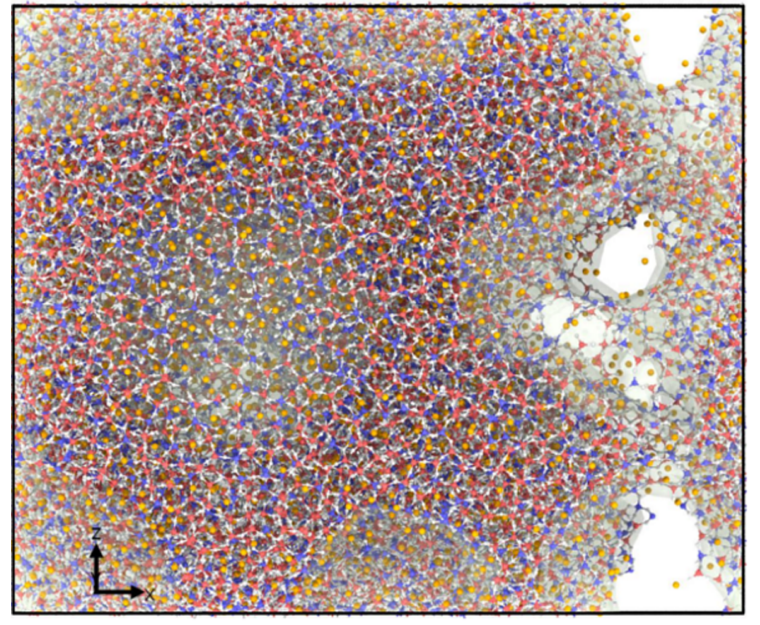

(a)

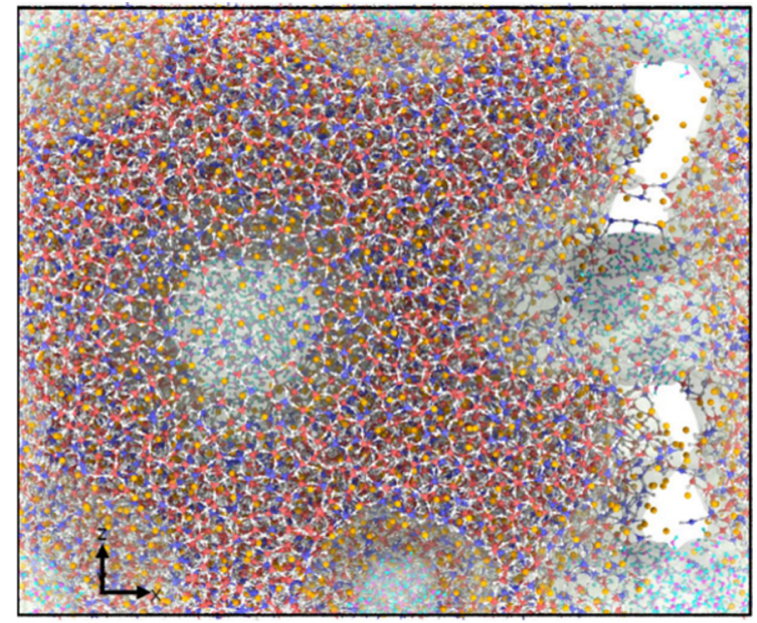

(b)

FIG. 4. Atomic configuration of: (a) GP2( $\left.\mathrm{W}_{\mathrm{i}}\right)$ and (b) $\mathrm{GP} 2 \mathrm{~W}_{\mathrm{i}}$ at failure ( 20\% strain).

the simulated and the experimentally obtained structures was observed, further confirming the reliability of the interatomic potentials and the adopted simulation procedure for obtaining geopolymer structures.

\section{B. Mechanical properties}

Uniaxial tensile deformation was applied on the equilibrated geopolymer structures using a constant strain rate of $0.001 / \mathrm{ps}\left(10^{9} / \mathrm{s}\right)$. Similar strain rates have been used by Muralidharan et al. ${ }^{50}$ for simulating the brittle fracture mechanism of silica glass under uniaxial tension. Effect of strain rates has been also studied for silica glass ${ }^{51}$ and silica nano wires ${ }^{52}$ which reports the use of similar strain rates $(0.001 / \mathrm{ps})$. Further, previous work on structurally and compositionally similar sodium aluminosilicate systems ${ }^{16}$ demonstrated that the choice of the strain rate $(=0.001 / \mathrm{ps})$ was low enough to allow for atomic restructuring mechanisms to occur in the stressed systems, while ensuring computational tractability, without affecting observed trends relating the composition and mechanical properties such as elastic modulus and ultimate tensile strength. The stress was calculated using the virial theorem ${ }^{53}$ and the respective stress-strain plots were obtained for all systems. For all $\mathrm{GPxW} / \mathrm{GPx}(\mathrm{W})$ systems failure occurred in a similar fashion, arising due to coalescence of a network of nano-voids present in the respective structures, which leads to the formation of the fracture surfaces as shown in Figure 4. In previous studies, it has been shown that the nano-voids serve as stressconcentrators. ${ }^{16,50}$

The ultimate tensile strength (UTS) was also obtained for all systems, by identifying the peak stress-value from the respective stress-strain curves while the elastic modulus was calculated from the initial slope of the stress-strain plot. As an example, the stress strain curve for structures with $\mathrm{Si} / \mathrm{Al}=2$ is shown in Figure 5. The variation of the

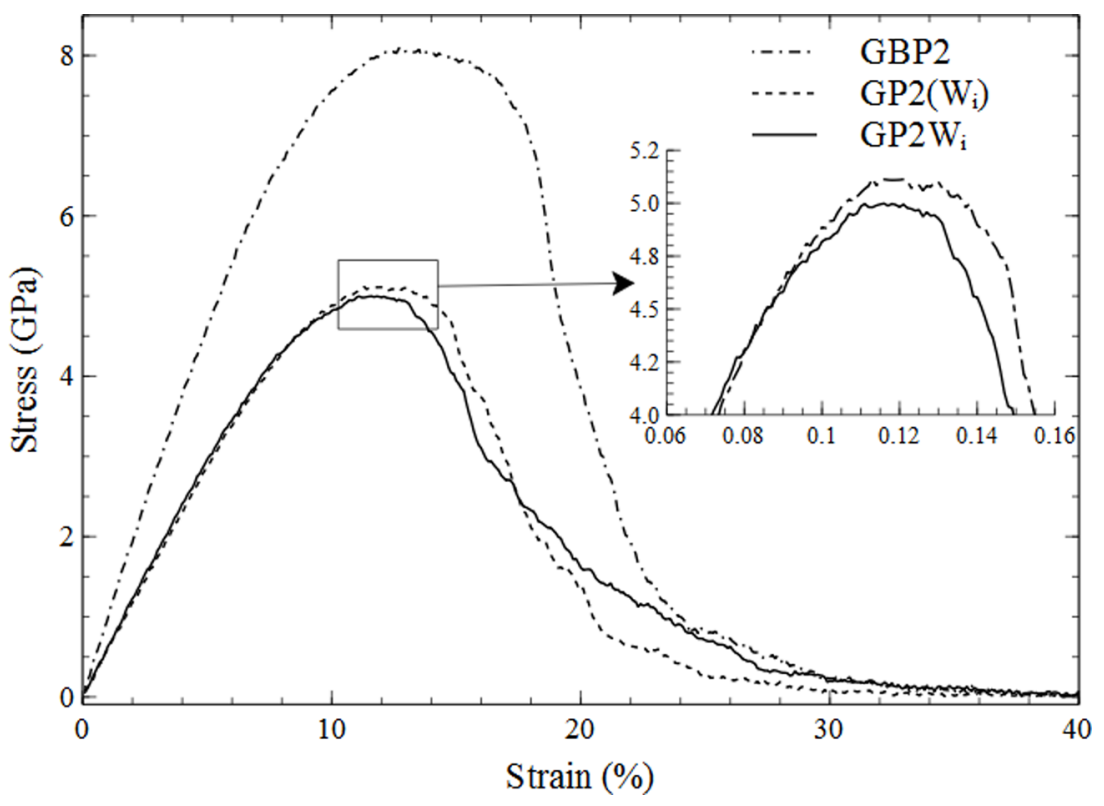

FIG. 5. Stress-strain plots for $\mathrm{Si} / \mathrm{Al}$ $=2$ under different conditions (GBP2, $\left.\mathrm{GP}_{2} \mathrm{~W}_{\mathrm{i}}, \mathrm{GP} 2\left(\mathrm{~W}_{\mathrm{i}}\right)\right)$; inset highlights the reduction of UTS due to the presence of water within nano voids. 


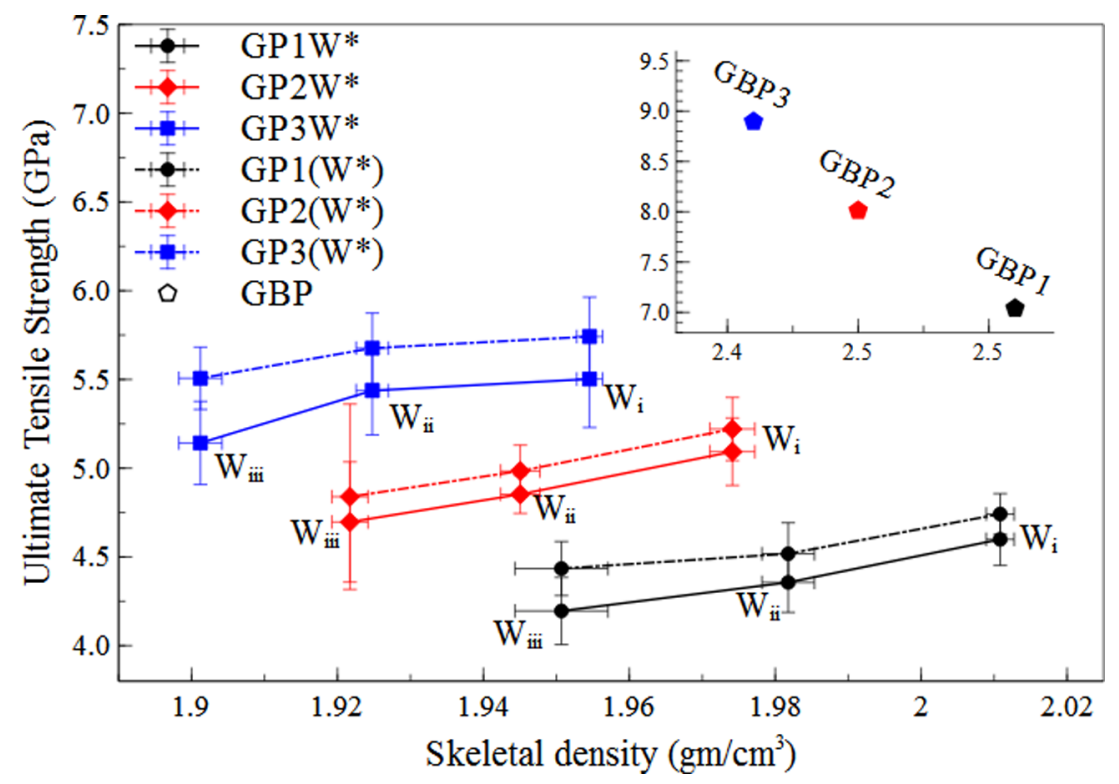

FIG. 6. Variation of ultimate tensile strength (UTS) as a function of skeletal density for different compositions and water content; inset shows the UTS (y-axis) as a function of densities ( $\mathrm{x}$ axis) for fully compacted GBP without the presence of water or voids; $\mathrm{W}^{*}$ represents water contents $\mathrm{W}_{\mathrm{i}}, \mathrm{W}_{\mathrm{ii}}$, and $\mathrm{W}_{\text {iii }}$ (increasing with decreasing skeletal density).

ultimate tensile strength (UTS) as a function of skeletal density for the different compositions is shown in Figure 6. Consistent with our previous work ${ }^{16}$ the UTS was found to increase with increasing $\mathrm{Si} / \mathrm{Al}$ ratio for both $\mathrm{GBP}$ and $\mathrm{GPx}(\mathrm{W}) / \mathrm{GPxW}$ systems. Also, for a given $\mathrm{Si} / \mathrm{Al}$ ratio, the GBP has a much higher UTS than the corresponding $\mathrm{GPx}(\mathrm{W}) / \mathrm{GPxW}$ systems. Further, increasing water content leads to a decrease in UTS for a given $\mathrm{Si} / \mathrm{Al}$ ratio. However, for a given skeletal density, the dehydrated $\mathrm{GPx}(\mathrm{W})$ systems demonstrate a higher UTS than the corresponding hydrated systems.

This systematic variation in UTS as a function of water content and skeletal density can be correlated to the underlying structure and diffusion properties of the $\mathrm{Na}$ ions as discussed below in Subsection IV C. Before we move on to Subsection IV $\mathrm{C}$, it is also worthwhile noting that the elastic modulus follows the same $\mathrm{Si} / \mathrm{Al}$ dependent trend as seen for UTS, consistent with the experimental findings of Duxson et al. ${ }^{54}$ However, the variation in the modulus as a function of water content was not significant.

\section{Effect of nano confined water on the structure and deformation}

To understand the effect of water on the GPxW structures, the structural evolution as a function of applied strain for the $\mathrm{GPx}(\mathrm{W})$ and the corresponding GPxW systems was compared. At zero strain, for all simulated systems, Si was found to be completely 4-fold coordinated. On the other hand, Al was found to be predominantly in the 4-fold state while a nontrivial amount of $\mathrm{AlO}_{3}$ ( $\mathrm{Al}$ coordinated to three oxygen atoms) was present. A lower amount of penta coordinated Al was also found in all systems. Here, the coordination of Si and Al atoms was calculated based on their bonding with oxygen atoms that belong to the 3-D polymeric network (i.e., structural oxygen, $\mathrm{O}_{\mathrm{s}}$ ). We assume that a $\mathrm{Si}$ (or $\mathrm{Al}$ ) bonds with an oxygen atom, if the distance of separation between the two atoms is less than $2.1 \AA$. The choice of this cutoff was based on the first minimum of the X-ray PDF as shown in Figure 3, which is also consistent with what was observed in a previous investigation of sodium aluminosilicate structures. ${ }^{16}$

Interestingly, NMR studies of geopolymers have always pointed out the predominance of tetrahedrally coordinated Al. ${ }^{5-10}$ However, the presence of three coordinated $\mathrm{Al}$ has been observed in metakaolin by White et al. ${ }^{55}$ further the relatively diminished presence of three coordinated $\mathrm{Al}$ (as reported in this work) may not be detected in NMR experiments possibly due to low signal to noise ratio ${ }^{56,57}$ and can be regarded as structural defects which are undetectable in experimental analysis.

In order to better facilitate the discussion, we focus on the $\mathrm{Si} / \mathrm{Al}=2$ systems; however, the trends observed for this ratio are equally applicable to the other ratios that were considered in this study.

Table III, which tabulates Al coordination population for $\mathrm{Si} / \mathrm{Al}=2$ points to the fact that in the equilibrated $\mathrm{GPx}(\mathrm{W})$ systems, the removal of water leads to a slight increase in $\mathrm{AlO}_{4}$ population (and a corresponding decrease in $\mathrm{AlO}_{3}$ population) as compared to the corresponding GPxW systems. Of note is the fact that even in systems containing water, none of the $\mathrm{Al}$ atoms were found to be coordinated with the oxygen atoms belonging to the water molecules $\left(\mathrm{O}_{\mathrm{w}}\right)$.

Figure 7 depicts the evolution in $\mathrm{Al}$ coordination as a function of strain. It is seen that with increasing strain, the decrease in the $\mathrm{AlO}_{4}$ population is higher for the hydrated GPxW systems as compared to the dehydrated $\operatorname{GPx}(\mathrm{W})$

TABLE III. Al coordination at zero strain for GP2 as a function of water content.

\begin{tabular}{lccc}
\hline \hline Name & $\mathrm{AlO}_{4}(\%)$ & $\mathrm{AlO}_{3}(\%)$ & $\mathrm{AlO}_{5}(\%)$ \\
\hline $\mathrm{GP} 2 \mathrm{~W}_{\mathrm{i}}$ & $95.31 \pm 0.49$ & $4.63 \pm 0.50$ & $0.07 \pm 0.02$ \\
$\mathrm{GP} 2\left(\mathrm{~W}_{\mathrm{i}}\right)$ & $95.44 \pm 0.20$ & $4.53 \pm 0.22$ & $0.04 \pm 0.03$ \\
$\mathrm{GP}_{\mathrm{ii}}$ & $95.47 \pm 0.21$ & $4.45 \pm 0.19$ & $0.09 \pm 0.04$ \\
$\mathrm{GP}\left(\mathrm{W}_{\text {ii }}\right)$ & $95.78 \pm 0.27$ & $4.12 \pm 0.23$ & $0.11 \pm 0.06$ \\
$\mathrm{GP} 2 \mathrm{~W}_{\text {iii }}$ & $96.01 \pm 0.47$ & $3.88 \pm 0.48$ & $0.11 \pm 0.04$ \\
$\mathrm{GP} 2\left(\mathrm{~W}_{\text {iii }}\right)$ & $96.235 \pm 0.42$ & $3.68 \pm 0.40$ & $0.09 \pm 0.03$ \\
\hline \hline
\end{tabular}




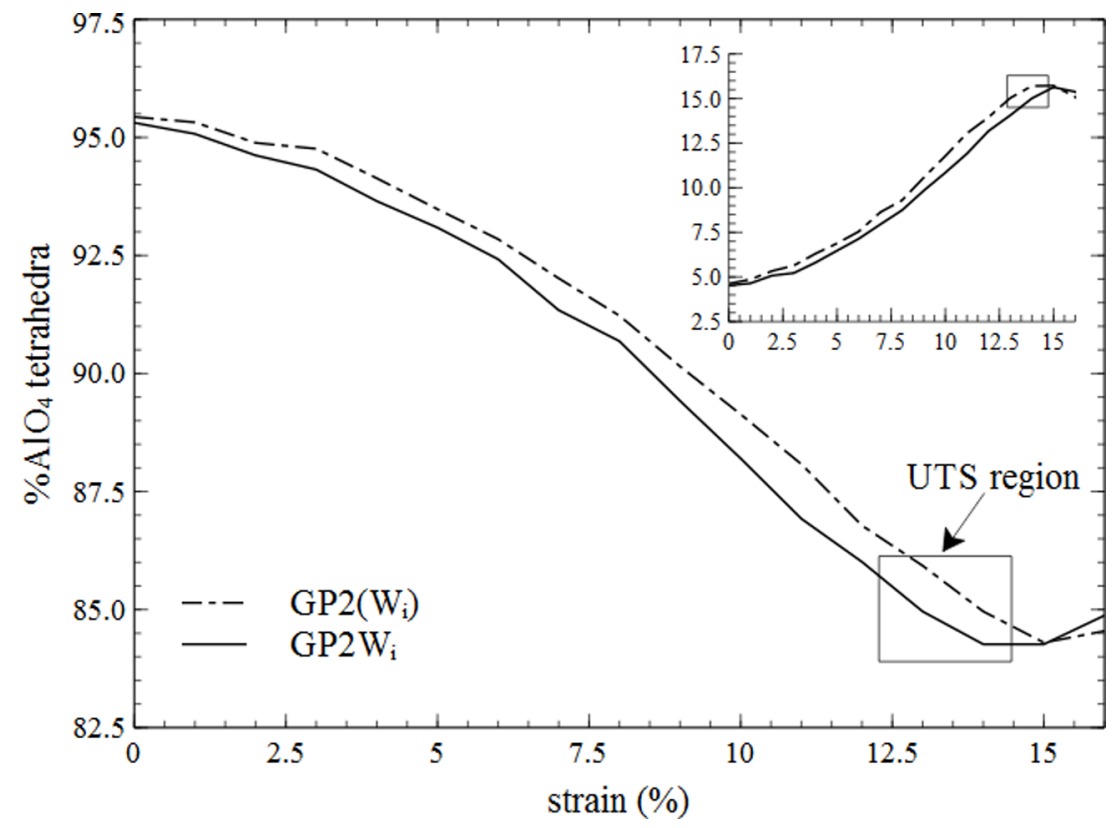

FIG. 7. Evolution of $\mathrm{AlO}_{4}$ tetrahedra population as a function of strain with and without water for $\mathrm{GP} 2 \mathrm{~W}_{\mathrm{i}}$; inset shows the corresponding evolution of $\mathrm{AlO}_{3}$ population.

systems. Further, the decrease in the $\mathrm{AlO}_{4}$ population is higher with increasing water content and as a consequence, leads to a corresponding reduction in UTS as pointed out in Figures 5 and 6. For all systems, a decrease in $\mathrm{AlO}_{4}$ population correlates exactly to a similar increase in $\mathrm{AlO}_{3}$ units confirming that the failure is always initiated by the breaking of $\mathrm{Al}-\mathrm{O}$ bonds in $\mathrm{AlO}_{4}$ units. A direct visualization of the MD simulation box shows that $\mathrm{AlO}_{3}$ units formed via the destabilization of the $\mathrm{AlO}_{4}$ units are primarily located near the failure surface formed due to the coalescence of the nano voids as seen in Figure 8. Very negligible change in $\mathrm{Si}$ coordination was seen at all strains (less than $0.3 \%)$.

Having established that failure is initiated by breaking Al-O bonds, we now turn our attention to understanding the interplay between water content and failure. Clearly, increasing water content leads to a relatively "faster" destabilization of the $\mathrm{AlO}_{4}$ units. Towards this end, we examine the role of $\mathrm{Na}$ ions on the stability of $\mathrm{AlO}_{4}$, given that the presence of the positive $\mathrm{Na}$ ions allows for charge balancing the negative charge on the $\mathrm{AlO}_{4}$ units.

Figure 9 depicts the mean squared displacement (MSD) of the Na ions during deformation. As seen from Figure 9, for a given pair of $\operatorname{GPx}(\mathrm{W})$ and $\mathrm{GPxW}$ systems, the presence of water molecules leads to a significant increase in the mobility of the $\mathrm{Na}$ ions. Consequently, this leads to destabilization of $\mathrm{AlO}_{4}$ units, leading to bond breakage and expediting failure. In particular, an inspection of the $\mathrm{AlO}_{3}$ units (or destabilized $\mathrm{AlO}_{4}$ units) shows that they are primarily located near the nano-voids (Figure 8) and the presence of water in these nano-voids provides a local polarization field that enhances $\mathrm{Na}$ mobility away from the $\mathrm{AlO}_{4}$ units. The increase in $\mathrm{Na}$ mobility coupled with the nano-voids serving as stress-concentrators leads to $\mathrm{Al}-\mathrm{O}$ bond breakage occurring predominantly in the vicinity of the nano-voids; this serves as the underlying mechanism governing the further growth and coalescence of the nano-voids ultimately leading to failure. In the absence of water, the nano-voids still serve as stress-concentrators and failure is still governed by $\mathrm{Al}-\mathrm{O}$ bond breakage near the nano-voids. However, the absence of water leads to higher overall stress required to initiate bond-breakage as seen by the corresponding higher UTS in the $\operatorname{GPx}(\mathrm{W})$ systems (noted in Figure 5).

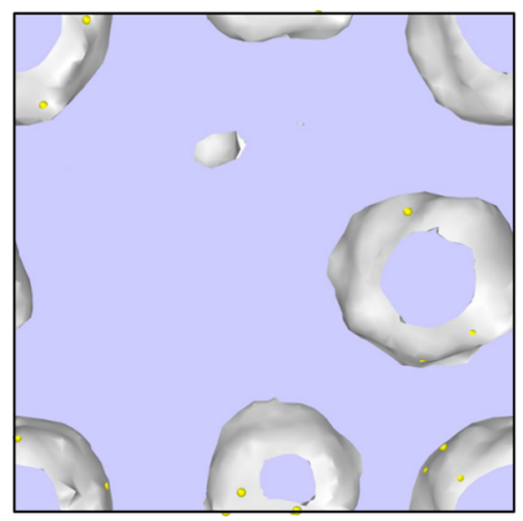

(a)

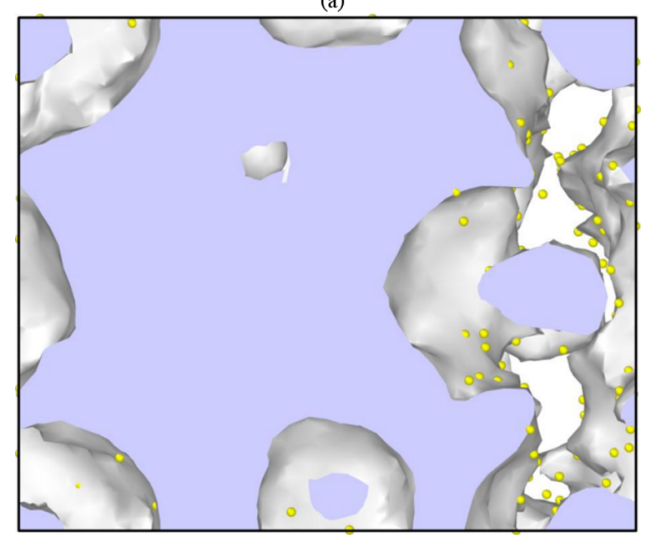

(b)

FIG. 8. Snapshots of $\mathrm{AlO}_{3}$ evolution at (a) equilibrium and at (b) $20 \%$ strain in the GP2Wi system. Yellow spheres indicate the three coordinated $\mathrm{Al}$ atoms (i.e., $\mathrm{AlO}_{3}$ ); as obvious from the figure the number of $\mathrm{AlO}_{3}$ increases significantly at $20 \%$ strain, and is typically present in the vicinity of the nano-voids. 


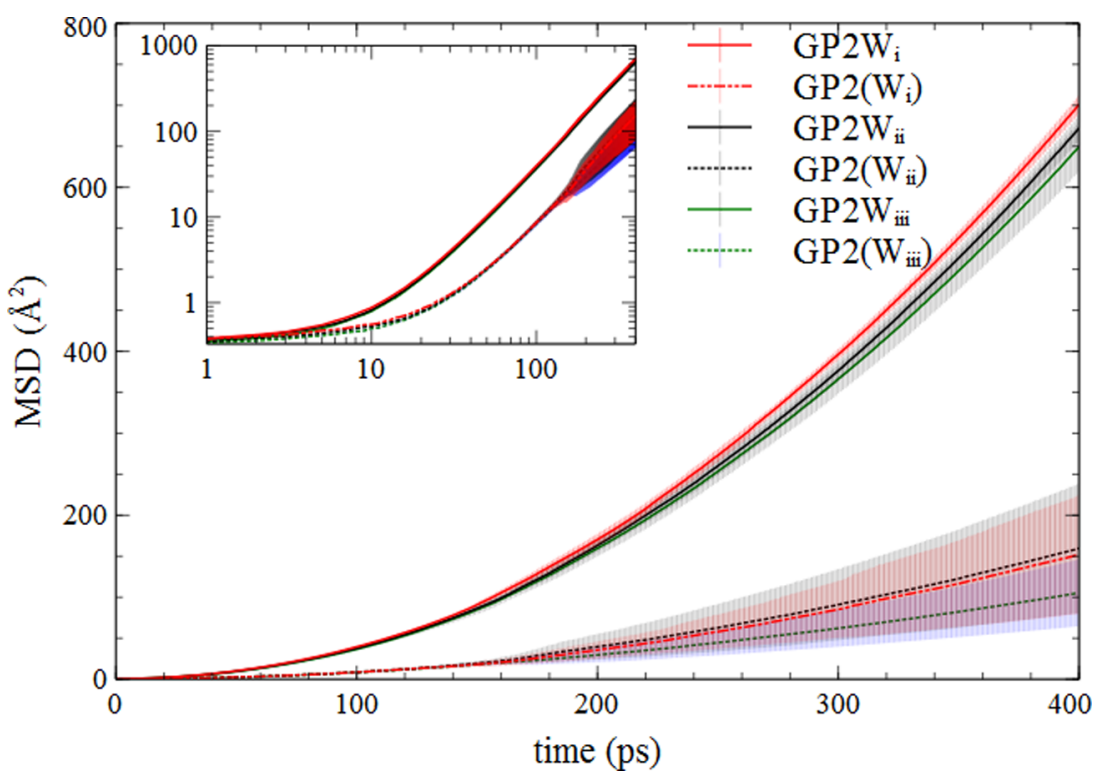

FIG. 9. Mean squared displacement (MSD) of $\mathrm{Na}$ atoms as a function of time during uniaxial deformation for different compositions with and without the presence of water within voids. Solid lines represent the MSD of structures with different water content within voids. Dashed lines represent the MSD of a structure after removing water from voids. Shades represent the error bars. The MSD implicitly includes the displacement of the $\mathrm{Na}$ atoms caused by the uniform uniaxial deformation of the MD simulation box. Inset shows the corresponding log-log plot.

Interestingly, the identification of the role of water on the destabilization of the $\mathrm{AlO}_{4}$ units leading to failure is of fundamental importance as it is very different than the hydrolytic weakening mechanism involving $\mathrm{Si}-\mathrm{O}$ bonds, which is typically accepted to be the chief mechanism of failure in most silicate materials. ${ }^{58,59}$ In this context, we have also carried out density functional theory (DFT) calculations focusing on estimating bond-energies of $\mathrm{Al}-\mathrm{O}$ and $\mathrm{Si}-\mathrm{O}$ in charge neutral molecules as discussed in Subsection IV D.

\section{Density functional theory (DFT) calculation of bond strength}

In order to shed further light on understanding the reasons underlying failure being exclusively driven by $\mathrm{Al}-\mathrm{O}$ bond-breakage, we carried out DFT calculations that compared the relative molecular binding energies of the molecules $\left(\mathrm{Al}(\mathrm{OH})_{3}, \mathrm{Al}(\mathrm{OH})_{4}, \mathrm{NaAl}(\mathrm{OH})_{4}\right.$, and $\mathrm{Si}(\mathrm{OH})_{4}$. $\mathrm{Al}(\mathrm{OH})_{3}$ and $\left.\mathrm{Si}(\mathrm{OH})_{4}\right)$, with the choice being motivated by the fact that these molecules represent the immediate chemical environment seen by $\mathrm{Al}$ and $\mathrm{Si}$ ions. Here, we use the binding energy as a measure of the relative bond strengths of $\mathrm{Al}-\mathrm{O}$ and $\mathrm{Si}-\mathrm{O}$. In all cases we used additional terminal $\mathrm{H}$ atoms to ensure charge balance. Calculations were performed using the quantum chemistry software package Gaussian (g09) ${ }^{60}$ within the framework of density functional theory (DFT). The basis set used for all atoms was $6-311 G(p, d)$. The exchange and correlation functional used were the hybrid functional of Becke and Lee-Yang-Parr (B3LYP). ${ }^{61,62}$

The binding energy $\Delta \mathrm{E}$ is calculated as given below and reported in Table IV,

$$
\Delta E=\frac{\left(E_{M(\mathrm{OH})_{x}}-E_{m}-x E_{\mathrm{OH}}-E_{\mathrm{Na}}\right)}{x},
$$

where $\mathrm{M}=\mathrm{Al}$ or $\mathrm{Si}$ and $\mathrm{x}=3$ or 4

$\mathrm{E}_{\mathrm{M}(\mathrm{OH}) \mathrm{x}}=$ total energy of $\mathrm{M}(\mathrm{OH})_{\mathrm{x}}$,

$\mathrm{E}_{\mathrm{M}}=$ ground state energy of $\mathrm{M}$,
$\mathrm{E}_{\mathrm{OH}}=$ total energy of $\mathrm{OH}$,

$\mathrm{E}_{\mathrm{Na}}=$ ground state energy of $\mathrm{Na}$.

For $\mathrm{NaAl}(\mathrm{OH})_{4}$, the interaction energy between $\mathrm{Na}$ and $\mathrm{OH}$ is subtracted from $\Delta \mathrm{E}$ to enable estimating and isolating the $\mathrm{Al}-\mathrm{O}(\mathrm{H})$ interaction energy.

In all calculations, the energy minimized structures were located without imposing any symmetry constraints. In addition, $\mathrm{Al}(\mathrm{OH})_{4}$ was also subjected to energy minimization while preserving the tetrahedral symmetry.

It is clear from Table IV that the bonding strength between $\mathrm{Si}$ and $\mathrm{O}$ is the strongest among all model compounds. When $\mathrm{Si}$ is substituted by $\mathrm{Al}$ in the tetrahedral structure, the binding energy becomes less negative or equivalently, the $\mathrm{Al}-\mathrm{O}$ bond strength in the tetrahedral structure is reduced. Further, the preferred geometry of $\mathrm{AlO}_{4}$ deviates from an ideal tetrahedral symmetry. However, in the presence of $\mathrm{Na}$, the tetrahedral geometry corresponds to the lowest energy configuration, with a simultaneous increase in the Al-O bond strength as seen in Table IV, confirming the fact that $\mathrm{Na}$ leads to stabilization of the $\mathrm{AlO}_{4}$ tetrahedron. Nevertheless, among all $\mathrm{Al}$ compounds, the 3-coordinated $\mathrm{Al}$ demonstrates the highest bond strength, which can be attributed to the valence electronic configuration of $\mathrm{Al}$. Thus one should expect that $\mathrm{Al}-\mathrm{O}$ bond breakage should be restricted to tetrahedrally coordinated $\mathrm{Al}$ ions as seen in the above reported $\mathrm{MD}$ simulations.

TABLE IV. The $\mathrm{M}-\mathrm{O}(\mathrm{H})$ binding energy $(\mathrm{kJ} / \mathrm{mol})$ and symmetry of model compounds.

\begin{tabular}{lll}
\hline \hline Compounds & $\Delta \mathrm{E}(\mathrm{kJ} / \mathrm{mol})$ & \multicolumn{1}{c}{ Symmetry } \\
\hline $\mathrm{Al}(\mathrm{OH})_{3}$ or $\left(\mathrm{AlO}_{3}\right) \mathrm{H}_{3}$ & -454.39 & Planar trigonal \\
$\mathrm{NaAl}(\mathrm{OH})_{4}$ or $\mathrm{Na}_{\left(\mathrm{AlO}_{4}\right) \mathrm{H}_{4}}$ & -438.72 & Tetrahedral \\
$\mathrm{Al}(\mathrm{OH})_{4}$ or $\left(\mathrm{AlO}_{4}\right) \mathrm{H}_{4}$ & -373.29 & Distorted tetrahedral \\
$\mathrm{Al}(\mathrm{OH})_{4}$ or $\left(\mathrm{AlO}_{4}\right) \mathrm{H}_{4}$ & -360.96 & Tetrahedral \\
$\mathrm{Si}(\mathrm{OH})_{4}$ or $\left(\mathrm{SiO}_{4}\right) \mathrm{H}_{4}$ & -489.00 & Tetrahedral \\
\hline \hline
\end{tabular}




\section{E. Diffusion of alkali $\left(\mathrm{Na}^{+}\right)$cations and water molecules under equilibrium conditions}

\section{Diffusion of $\mathrm{Na}$ atoms}

Clearly, Na mobility is intimately linked to the mechanical response of the $\mathrm{GPx}(\mathrm{W}) / \mathrm{GPxW}$ systems. In this context, we examine the diffusion characteristics of $\mathrm{Na}$ even in the absence of deformation. This enables fundamental insight into the equilibrium properties of geopolymers. Towards this end, we present the mean-squared displacement (MSD) averaged over all $\mathrm{Na}$ ions present in the respective systems at zero strain. The MSD of each $\mathrm{Na}$ atom was recorded at 50 ps intervals for a total production run of 4 ns (Figure 10). For the sake of clarity, we compare and contrast $\mathrm{Na}$ diffusion for a given pair of $\mathrm{GPx}(\mathrm{W}) / \mathrm{GPxW}$ when $\mathrm{Si} / \mathrm{Al}$ ratio equals 1 . We chose this system since the number of counterbalancing $\mathrm{Na}$ ions is highest. As seen in Figure 10, the presence of water within the pores enhances alkali diffusion, consistent with experimental observation of enhancement in alkali leaching in geopolymers when exposed to water. ${ }^{14,15}$ Inset of Figure 10 shows the $\log -\log$ plot of MSD vs. time to illustrate the three different regimes of Na diffusion. The initial ballistic motion occurs up to $0.3 \mathrm{ps}$, followed by a plateau caged regime and then diffusive regime.

On a different note, a comparison between Figures 9 and 10 shows that the MSD of Na ions is orders of magnitude greater in both GPx $(\mathrm{W})$ and GPxW systems when subjected to deformation. This can be attributed to the application of a uniform strain at a constant rate to the system which leads to much larger "forced" displacements of all atoms within the simulation box. Further, the fact that in the deformed systems there is significant $\mathrm{Al}-\mathrm{O}$ bond breakage also affects the mobility of the Na ions. Specifically, the destabilization of $\mathrm{Al}$ tetrahedra allows the previously loosely bound $\mathrm{Na}$ ions to migrate faster through the structural network, leading to the much larger observed MSD in the systems that undergo deformation. However, for both deformed and undeformed systems, the presence of water always enhances $\mathrm{Na}$ diffusion.
Typically, in MD simulations, the diffusion coefficient $\mathrm{D}$ is calculated in terms of the MSD $\left(\left\langle\left|\vec{r}(t)-\vec{r}\left(t_{0}\right)\right|^{2}\right\rangle\right)$ via the Einstein relation [Eq. (6)]

$$
D=\lim _{t \rightarrow \infty} \frac{\left\langle\left|\vec{r}(t)-\vec{r}\left(t_{0}\right)\right|^{2}\right\rangle}{6\left(t-t_{0}\right)},
$$

where $\overrightarrow{r(t)}$ is the position of the atom at time $\mathrm{t}$ and $\mathrm{t}_{\mathrm{o}}$ refers to the initial time. But Eq. (2) is applicable only for linear diffusion that follows Fick's law. In our case, Na diffusion was found to be anomalous (nonlinear with time) as shown in Figure 10. Specifically, for Na, the MSD vs time (t) behavior is obtained via the power law ${ }^{63}$ [see Eq. (7)]

$$
\left\langle r^{2}(t)\right\rangle=6 \Gamma t^{\alpha},
$$

where $\Gamma$ is a constant. If $\alpha<1$ then the system is called "subdiffusive," $\alpha>1$ is "superdiffusive." It is interesting to notice that at zero strain the diffusion of $\mathrm{Na}$ is "subdiffusive" where $\alpha<1$ (see Figure 10).

Further, for anomalous diffusion, the diffusion constant is referred to as an apparent diffusion constant and given by [Eq. (8)]. ${ }^{63}$ Specifically, for the particular system under consideration (GP1Wi) the calculated apparent diffusion coefficient was found to be $9.23 \times 10^{-13} \pm 5 \times 10^{-14} \mathrm{~m}^{2} / \mathrm{s}$,

$$
D(t)=\Gamma t^{\alpha-1} .
$$

Interestingly, a comparison of the apparent diffusion coefficients of $\mathrm{Na}$ within the different GP systems with available experimental data as observed by Lloyd et al. ${ }^{64}$ shows that the predicted diffusion coefficients are in accordance with the observed experimental values. Table $\mathrm{V}$ summarizes the experimentally obtained diffusion coefficients of $\mathrm{Na}$ ions by Lloyd et al. ${ }^{64}$ and the calculated diffusion coefficients from our MD simulations. It should be noted that the experimental results of Lloyd et al. ${ }^{64}$ only report the initial water content of the geopolymer mixture and the Na diffusion coefficient of the unhardened "early-stage" geopolymer paste. Nevertheless, despite the differences in conditions between the

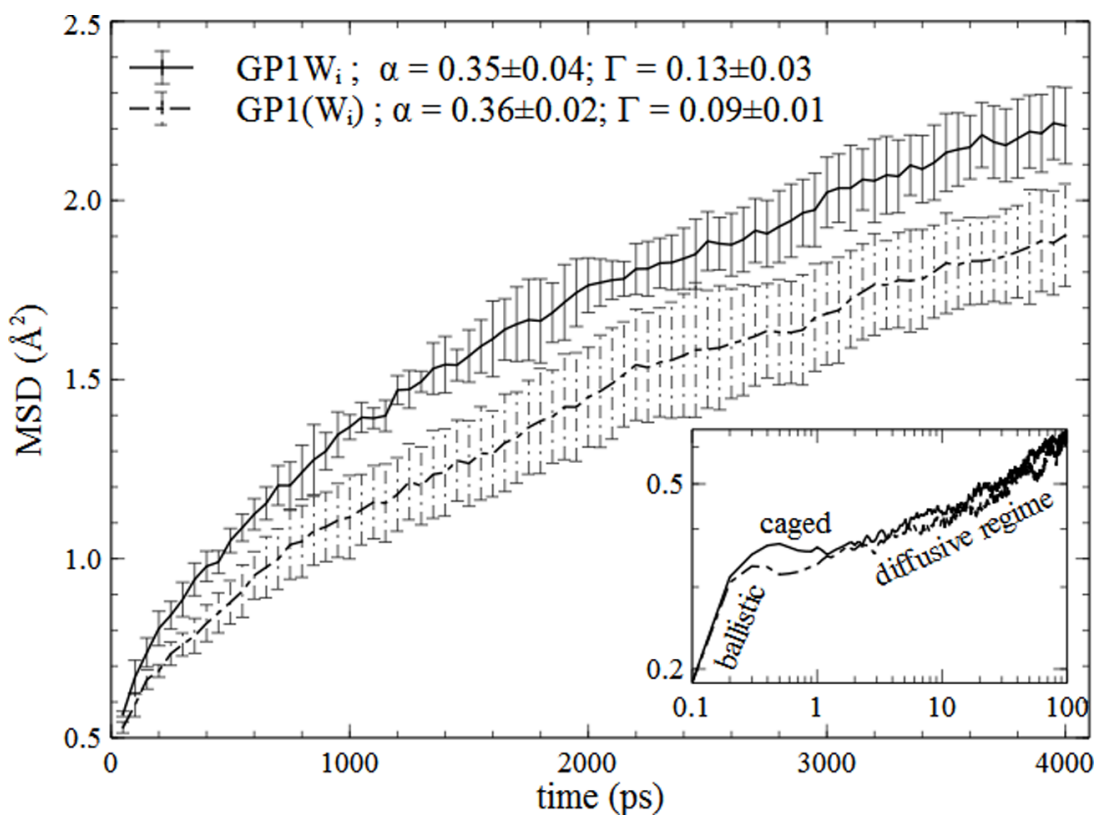

FIG. 10. Mean-squared-displacement of $\mathrm{Na}$ vs. time for $\mathrm{GP}_{\mathrm{W}}$ and $\mathrm{GP} 1\left(\mathrm{~W}_{\mathrm{i}}\right)$ at $0 \%$ strain. Solid lines represent the MSD of $\mathrm{Na}$ atoms influenced by water within voids, and dotted lines represent the cases corresponding to the dehydrated counterparts. Each curve was averaged over six independent NVE ensemble runs for $4 \mathrm{~ns}$; the $\alpha$ and $\Gamma$ values reported were obtained by fitting to a power law [Eq. (7)]. Inset shows the $\log -\log$ plot highlighting different regimes (ballistic, caged, and diffusive) of the MSD curves. 
TABLE V. Comparison of simulated and experimental Na diffusivity.

\begin{tabular}{lcccc}
\hline \hline $\begin{array}{l}\text { Diffusion coefficient observed experimentally by } \\
\text { Lloyd } \text { et }_{\text {al. }}{ }^{64} \text { for geopolymer paste }\end{array}$ & & \multicolumn{2}{l}{$\begin{array}{l}\text { Apparent diffusion coefficient calculated from } \\
\text { MD simulations in this study for GP1W structures }\end{array}$} \\
\cline { 1 - 2 } \cline { 5 - 6 } Initial water content (\%) & Diffusion coefficient $\left(\mathrm{m}^{2} / \mathrm{s}\right)$ & & Water content $(\%)$ & Diffusion coefficient $\left(\mathrm{m}^{2} / \mathrm{s}\right)$ \\
\hline 27.5 & $4.7 \times 10^{-12}$ & & 0 & $7.82 \times 10^{-13} \pm 7.27 \times 10^{-14}$ \\
32.5 & $7.3 \times 10^{-12}$ & & 2.6 & $9.23 \times 10^{-13} \pm 5 \times 10^{-14}$ \\
37.5 & $27 \times 10^{-12}$ & & 4.7 & $10.12 \times 10^{-13} \pm 6.5 \times 10^{-14}$ \\
\hline \hline
\end{tabular}

experiments and the current simulations at which $\mathrm{Na}$ diffusion was evaluated, it is clear that increasing water content leads to an increase in the diffusion coefficient of $\mathrm{Na}$, as seen by our MD simulation studies. This lends credence to our hypothesis that the polarization field arising due to the presence of the water molecules enhances $\mathrm{Na}$ diffusion. However, doing a more detailed analysis to validate this hypothesis is beyond the scope of this paper, and will form the basis of future work in this regard.

Towards this end, we further quantify $\mathrm{Na}$ diffusion by examining whether dynamical heterogeneity (DH) arises in $\mathrm{Na}$ diffusion in the presence/absence of water. In particular, in the presence of water one should expect more prominent DH effects given that water molecules are mostly found within the voids, thereby biasing $\mathrm{Na}$ diffusion found in their vicinity. In MD, DH is quantified by calculating the non-Gaussian parameter ${ }^{65}$ as discussed below, which is given by

$$
N G P(t)=\frac{3\left\langle r^{4}(t)\right\rangle}{5\left\langle r^{2}(t)\right\rangle}-1 .
$$

Here, $\left\langle r^{2}(t)\right\rangle$ is the mean squared displacement (MSD) of the atoms. For a homogenous system which obeys Brownian diffusion, NGP (t) equals to zero, while it is greater than zero when there are dynamical heterogeneities (DH). The variation in NGP for a $\mathrm{Si} / \mathrm{Al}$ ratio of 1 as a function of water content is given in Figure 11 and points to the fact that as we increase water content the DH increases correspondingly. In addition, Figure 12 depicts the displacement-trajectory of $\mathrm{Na}$ atoms near and away from water within the bulk geopolymer. It is clear from Figure 12 that $\mathrm{Na}$ atoms in the vicinity of water demonstrate higher MSD even in the absence of external mechanical stimulus further confirming the interplay between presence of water and $\mathrm{Na}$ diffusion. Thus, the higher NGP values point to the fact that the $\mathrm{Na}$ atoms near water have much higher mobilities as compared to other $\mathrm{Na}$ atoms. Furthermore, the NGP of GP1 $\left(\mathrm{W}_{\mathrm{i}}\right)$ in Figure 11 reaches a maximum value at around $75 \mathrm{ps}$, which can be correlated to the transition from the caged regime to the diffusive as shown in Figure 10. Similar phenomena have been also observed for aluminosilicate melts in the MD study made by Hoang et al. ${ }^{66}$

\section{Diffusion of water molecules}

To complement the $\mathrm{Na}$ diffusion studies, we also examined the mobility of water molecules, since water within geopolymers has been found to be tightly bound as opposed to being highly mobile in semi-crystalline systems as seen from NMR spectra. ${ }^{67}$ Towards this end, we calculated the diffusion coefficient of water molecules in the $\mathrm{GP} 1 \mathrm{~W}_{\mathrm{i}}$ as well as the self-diffusion coefficient in bulk water. Samples corresponding to the equilibrium density of bulk water $\left(0.999 \mathrm{gm} / \mathrm{cm}^{3}\right)$ were used for obtaining the self-diffusion coefficient. A linear diffusion behavior was observed for bulk water (Figure 13(a)) and thus the Einstein relation [Eq. (6)] was used to calculate the diffusion coefficient. The diffusion coefficient for bulk water was estimated as $3.10 \times 10^{-9} \pm 3.72 \times 10^{-11} \mathrm{~m}^{2} / \mathrm{s}$ consistent with experimental

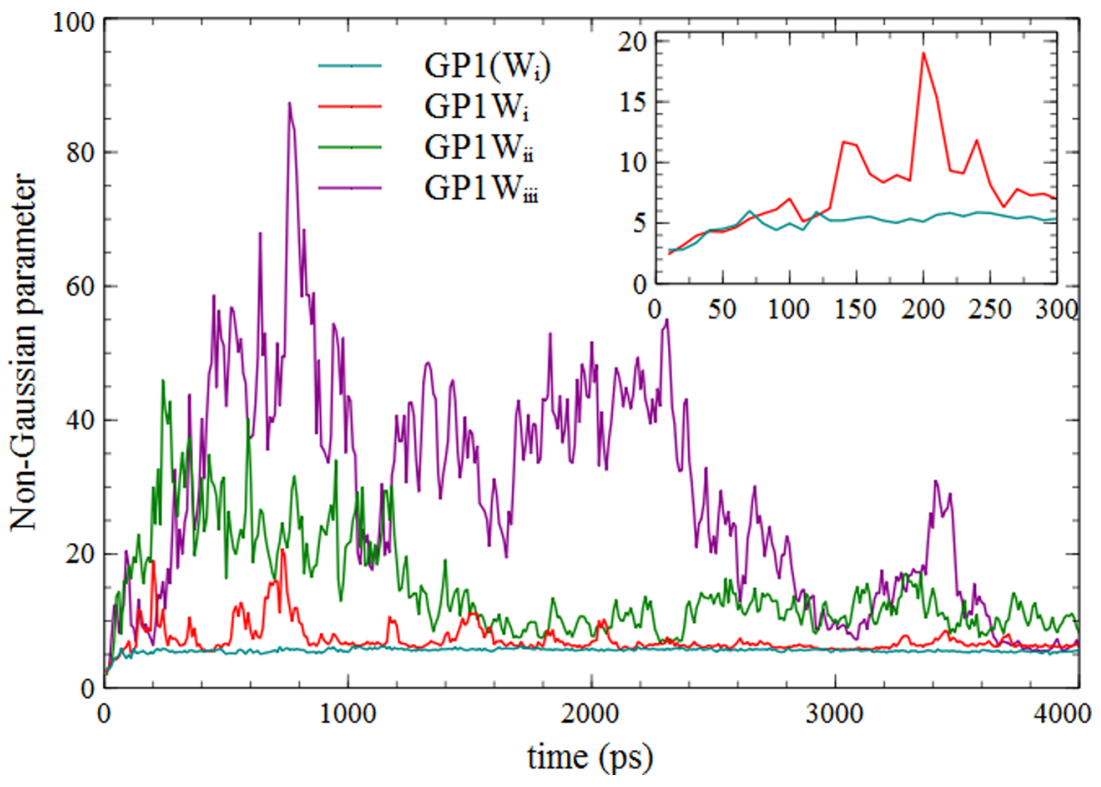

FIG. 11. Time evolution of the nonGaussian parameter for the GP1 system as a function of water content. Inset shows the zoomed view of NGP for $\mathrm{GP} 1\left(\mathrm{~W}_{\mathrm{i}}\right)$ and $\mathrm{GP} 1 \mathrm{~W}_{\mathrm{i}}$. 


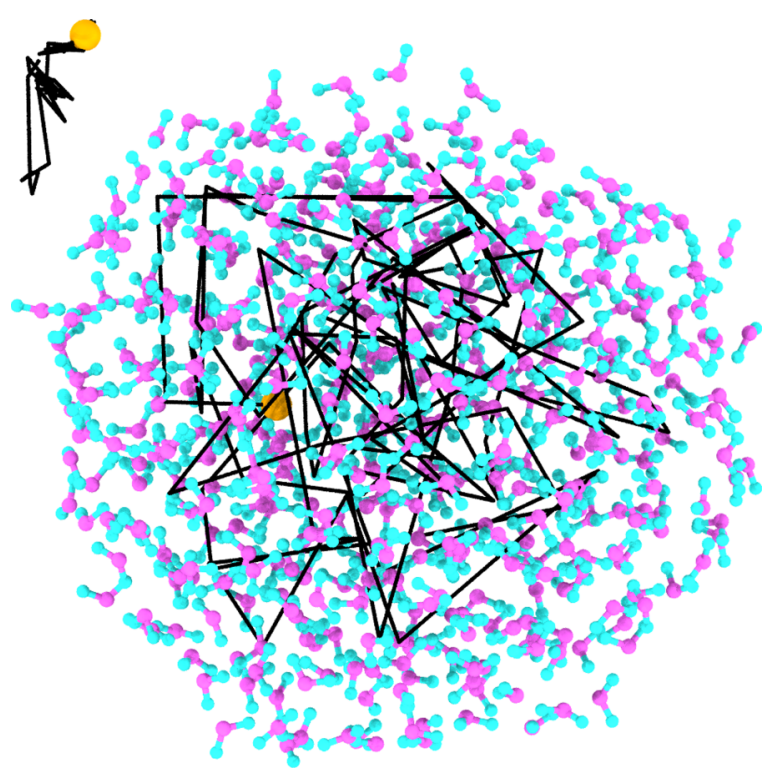

FIG. 12. Illustration of the displacement-trajectory of a typical Na atom in the vicinity of water molecules; for comparison, the trajectory of a $\mathrm{Na}$ atom away from water molecules but within the bulk region of geopolymer binder is also shown in the top-left corner.

values. ${ }^{68}$ However, the diffusion behavior of confined water molecules trapped within the voids of geopolymer was found to be "anomalous" or "subdiffusive" with a much smaller $\alpha$ value of $0.08 \pm 0.01$ (see Figure 13(b)) as compared to that of

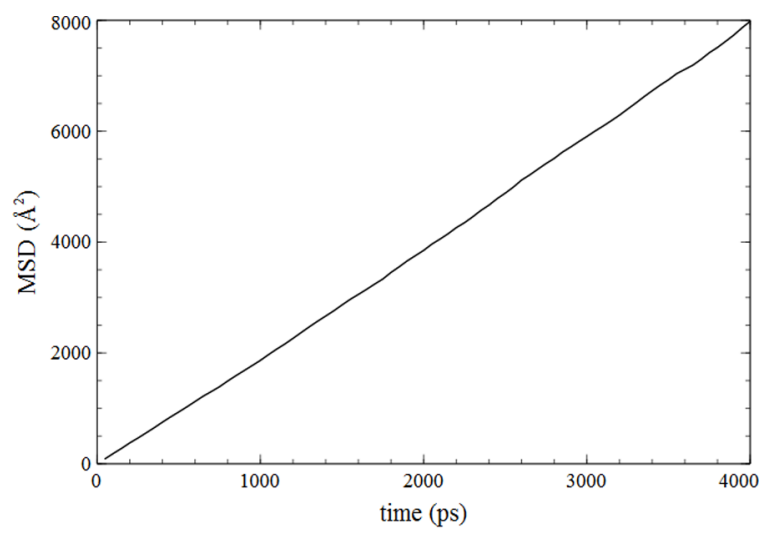

(a)

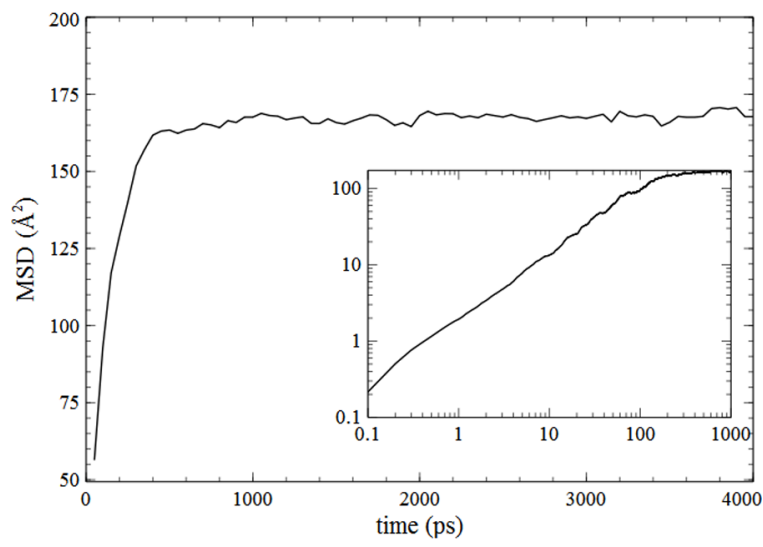

(b)

FIG. 13. Mean squared displacement for the center of mass of all water molecules for (a) bulk water, (b) water within the voids of geopolymer binder for $\mathrm{GP}_{1} \mathrm{~W}_{\mathrm{i}}$. Inset in (b) shows the log-log plot of water diffusion.
Na. Unlike the Na diffusion in Figure 10, the water molecules are trapped within the nano voids of the geopolymer which is manifested by their restricted MSD in Figure 13(b). The calculated apparent diffusion coefficient of water molecules for $\mathrm{GP}_{1} \mathrm{~W}_{\mathrm{i}}$ structure was found to be $7.33 \times 10^{-11} \pm 4.02$ $\times 10^{-12} \mathrm{~m}^{2} / \mathrm{s}$. Interestingly, previous Quasi-Elastic Neutron Scattering (QENS) and MD simulation results both show that in $\mathrm{NaX}$ and $\mathrm{NaY}$ zeolites, water diffusion is highly restricted too. ${ }^{69}$

\section{SUMMARY AND CONCLUSION}

The findings of the current work can be summarized as below:

1. The ultimate tensile strength (UTS) and elastic modulus of the MD simulated geopolymer binder increase with the increasing $\mathrm{Si} / \mathrm{Al}$ ratios. For a given $\mathrm{Si} / \mathrm{Al}$ ratio, the UTS decreases with increasing water content and decreases in skeletal density. Removing water from the voids present in the geopolymer network does not affect the $\mathrm{Si}-\mathrm{Al}$ framework structure but results in an increase in the UTS. However, the elastic modulus of the binder is not significantly altered due to the removal of water.

2. Failure of geopolymers is initiated via $\mathrm{Al}-\mathrm{O}$ bond breakage. In particular, the $\mathrm{Al}$ tetrahedron is characterized by weaker bonds as compared to the $\mathrm{Si}$ tetrahedron as observed from the MD simulations and also supported by the DFT calculations.

3. The presence of water in the nano voids has a significant impact on the deformation dynamics of geopolymers. Specifically, Na diffusion was found to be greatly enhanced in the presence of water, leading to a faster destabilization of Al tetrahedra.

4. The destabilization of the $\mathrm{AlO}_{4}$ tetrahedra due to water underlies the mechanical failure of geopolymers. This is in contrast to the hydrolytic weakening mechanisms that are known to occur in other silicate materials.

5. Both $\mathrm{Na}$ and molecular water show anomalous diffusion behavior in geopolymers. Water molecules are tightly bound within the voids of geopolymers showing much lower diffusivity compared to bulk water. In the geopolymers $\mathrm{Na}$ diffusion shows dynamic heterogeneity (DH) due to the presence of water and its extent increases with the increment of water content.

The findings of this study provide a fundamental understanding of the molecular mechanisms that govern the mechanical response of geopolymers. While we have only focused on elucidating the role of molecular water, in the future we will develop reactive force fields (i.e., ReaxFF ${ }^{70}$ ) that will explicitly account for the disassociation of water and its interplay with the alkali cations and their combined effect on the mechanical response of geopolymers. The next steps that will help in extending the scope of the current work will involve coupling the MD simulations to a larger scale finite element method (FEM) and/or peridynamics simulations in order to account for the presence of macroscopic voids and 
unreacted phases that are present within the geopolymer composite. Currently, work is underway in this regard.

${ }^{1}$ J. Davidovits, J. Therm. Anal. 37, 1633 (1991).

${ }^{2}$ S. Ahmari, X. Ren, V. Toufigh, and L. Zhang, Constr. Build. Mater. 35, 718 (2012).

${ }^{3}$ X. Ren, L. Zhang, D. Ramey, B. Waterman, and S. Ormsby, J. Mater. Sci. 50, 1370 (2014).

${ }^{4}$ R. Shadnia, L. Zhang, and P. Li, Constr. Build. Mater. 84, 95 (2015).

${ }^{5}$ P. Duxson, J. L. Provis, G. C. Lukey, F. Separovic, and J. S. J. van Deventer, Langmuir 21, 3028 (2005).

${ }^{6}$ P. S. Singh, M. Trigg, I. Burgar, and T. Bastow, Mater. Sci. Eng. A 396, 392 (2005).

${ }^{7}$ V. F. F. Barbosa, K. J. D. MacKenzie, and C. Thaumaturgo, Int. J. Inorg. Mater. 2, 309 (2000).

${ }^{8}$ H. Rahier, B. Mele, M. Biesemans, J. Wastiels, and X. Wu, J. Mater. Sci. 31, 71 (1996)

${ }^{9}$ P. Duxson, A. Fernández-Jiménez, J. L. Provis, G. C. Lukey, A. Palomo, and J. S. J. van Deventer, J. Mater. Sci. 42, 2917 (2007).

${ }^{10}$ P. Duxson, G. C. Lukey, F. Separovic, and J. S. J. van Deventer, Ind. Eng. Chem. Res. 44, 832 (2005).

${ }^{11}$ P. Duxson, G. Lukey, and J. van Deventer, J. Mater. Sci. 42, 3044 (2007).

${ }^{12}$ C. E. White, J. L. Provis, T. Proffen, and J. S. J. Van Deventer, J. Am. Ceram. Soc. 93, 3486 (2010).

${ }^{13}$ Y. Fang and O. Kayali, Constr. Build. Mater. 39, 89 (2013).

${ }^{14}$ F. Skvára, L. Kopecký, V. Smilauer, and Z. Bittnar, J. Hazard. Mater. 168, 711 (2009).

${ }^{15}$ E. Najafi, A. Allahverdi, and J. L. Provis, Cem. Concr. Compos. 34, 25 (2012).

${ }^{16}$ M. Sadat, S. Bringuier, K. Muralidharan, A. Asaduzzaman, K. Runge, and L. Zhang, J. Non-Cryst. Solids 434, 53 (2016).

${ }^{17}$ W. Kriven, J. Bell, and M. Gordon, Adv. Ceram. Matrix Compos. IX, 227 (2003).

${ }^{18}$ W. M. Kriven, J. L. Bell, and M. Gordon, Ceram. Eng. Sci. Proc. 27, 491-503 (2006).

${ }^{19}$ M. Bauchy, M. J. A. Qomi, F.-J. Ulm, and R. J.-M. Pellenq, J. Chem. Phys. 140, 214503 (2014).

${ }^{20}$ H. Manzano, E. Masoero, I. Lopez-Arbeloa, and H. M. Jennings, Soft Matter 9, 7333 (2013).

${ }^{21}$ M. Bauchy, H. Laubie, M. J. Abdolhosseini Qomi, C. G. Hoover, F.-J. Ulm, and R. J.-M. Pellenq, J. Non-Cryst. Solids 419, 58 (2015).

${ }^{22}$ M. J. A. Qomi, M. Bauchy, F.-J. Ulm, and R. J.-M. Pellenq, J. Chem. Phys. 140, 54515 (2014).

${ }^{23}$ D. Hou, Y. Zhu, Y. Lu, and Z. Li, Mater. Chem. Phys. 146, 503 (2014).

${ }^{24}$ R. J.-M. Pellenq, A. Kushima, R. Shahsavari, K. J. Van Vliet, M. J. Buehler, S. Yip, and F.-J. Ulm, Proc. Natl. Acad. Sci. U. S. A. 106, 16102 (2009).

${ }^{25}$ D. Hou, Z. Li, and T. Zhao, RSC Adv. 5, 448 (2015).

${ }^{26}$ C. White, J. Provis, T. Proffen, and J. van Deventer, AIChE J. 58, 2241 (2012).

${ }^{27}$ R. Chanajaree, P. A. Bopp, S. Fritzsche, and J. Kärger, Microporous Mesoporous Mater. 146, 106 (2011).

${ }^{28}$ D. A. Faux, W. Smith, and T. R. Forester, J. Phys. Chem. B 101, 1762 (1997).

${ }^{29}$ S. Sperinck, P. Raiteri, N. Marks, and K. Wright, J. Mater. Chem. 21, 2118 (2011).

${ }^{30}$ G. Malavasi, M. C. Menziani, A. Pedone, and U. Segre, J. Non-Cryst. Solids 352, 285 (2006).

${ }^{31}$ J. Du and A. N. Cormack, J. Non-Cryst. Solids 349, 66 (2004).

${ }^{32}$ V. A. Bakaev and W. A. Steele, J. Chem. Phys. 111, 9803 (1999).

${ }^{33}$ A. Tilocca, N. de Leeuw, and A. Cormack, Phys. Rev. B 73, 104209 (2006).

${ }^{34}$ M. Bauchy, J. Chem. Phys. 137, 44510 (2012).

${ }^{35}$ S. Sperinck, Metakaolin as a Model System for Understanding Geopolymers (Curtin University, 2012).

${ }^{36}$ Y. Wu, H. L. Tepper, and G. A. Voth, J. Chem. Phys. 124, 24503 (2006).

${ }^{37}$ R. W. Hockney and J. W. Eastwood, Computer Simulation Using Particles (CRC Press, 1988).

${ }^{38}$ S. Plimpton, J. Comput. Phys. 117, 1 (1995).
${ }^{39}$ A. Stukowski, Modell. Simul. Mater. Sci. Eng. 18, 15012 (2010).

${ }^{40}$ L. Martinez, R. Andrade, E. G. Birgin, and J. M. Martinez, J. Comput. Chem. 30, 2157 (2009).

${ }^{41}$ A. N. Cormack and Y. Cao, Mol. Eng. 6, 183 (1996).

${ }^{42}$ J. Du and A. N. Cormack, J. Am. Ceram. Soc. 88, 2532 (2005).

${ }^{43}$ S. Le Roux and P. Jund, Comput. Mater. Sci. 49, 70 (2010).

${ }^{44}$ C. Massobrio, J. Du, M. Bernasconi, and P. Salmon, Molecular Dynamics Simulations of Disordered Materials from Network Glasses to PhaseChange Memory Alloys (Springer, New York, 2015).

${ }^{45}$ J. L. Bell, P. Sarin, J. L. Provis, R. P. Haggerty, P. E. Driemeyer, P. J. Chupas, J. S. J. van Deventer, and W. M. Kriven, Chem. Mater. 20, 4768 (2008).

${ }^{46}$ C. Meral, C. J. Benmore, and P. J. M. Monteiro, Cem. Concr. Res. 41, 696 (2011).

${ }^{47}$ J. Melar, G. Renaudin, F. Leroux, A. Hardy-Dessources, J.-M. Nedelec, C. Taviot-Gueho, E. Petit, P. Steins, A. Poulesquen, and F. Frizon, J. Phys. Chem. C 119, 17619 (2015).

${ }^{48}$ J. L. Bell, P. Sarin, P. E. Driemeyer, R. P. Haggerty, P. J. Chupas, and W. M. Kriven, J. Mater. Chem. 18, 5974 (2008).

${ }^{49}$ C. E. White, K. Page, N. J. Henson, and J. L. Provis, Appl. Clay Sci. 73, 17 (2013).

${ }^{50}$ K. Muralidharan, K.-D. Oh, P. A. Deymier, K. Runge, and J. H. Simmons, J. Mater. Sci. 42, 4159 (2007).

${ }^{51}$ A. Pedone, G. Malavasi, M. Cristina Menziani, U. Segre, and A. N. Cormack, Chem. Mater. 20, 4356 (2008).

${ }^{52}$ F. Yuan and L. Huang, J. Non-Cryst. Solids 358, 3481 (2012).

${ }^{53}$ M. P. Allen and D. J. Tildesley, Computer Simulation of Liquids (Claredon Press, New York, 1987).

${ }^{54}$ P. Duxson, S. Mallicoat, G. Lukey, W. M. Kriven, and J. S. J. van Deventer, Colloids Surf. A 292, 8 (2007).

${ }^{55}$ C. E. White, J. L. Provis, T. Proffen, D. P. Riley, and J. S. J. van Deventer, Phys. Chem. Chem. Phys. 12, 3239 (2010).

${ }^{56}$ E. Lippmaa, M. Mägi, A. Samoson, G. Engelhardt, and A. R. Grimmer, J. Am. Chem. Soc. 102, 4889 (1980).

${ }^{57}$ A. D. Irwin, J. S. Holmgren, and J. Jonas, J. Mater. Sci. 23, 2908 (1988).

${ }^{58}$ D. Griggs, Geophys. J. R. Astron. Soc. 14, 19 (1967).

${ }^{59}$ D. Hou, H. Ma, Z. Li, and Z. Jin, Acta Mater. 80, 264 (2014).

${ }^{60}$ M. J. Frisch, G. W. Trucks, H. B. Schlegel, G. E. Scuseria, M. A. Robb, G. Cheeseman, J. R. Scalmani, V. Barone, B. Mennucci, G. A. Petersson, H. Nakatsuji, M. Caricato, X. Li, H. P. Hratchian, A. F. Izmaylov, J. Bloino, G. Zheng, J. L. Sonnenberg, K. Hada, M. Ehara, M. Toyota, R. Fukuda, J. Hasegawa, M. Ishida, T. Nakajima, Y. Honda, O. Kitao, H. Nakai, T. Vreven, J. A. Montgomery, Jr., J. E. Peralta, F. Ogliaro, M. Bearpark, J. J. Heyd, E. Brothers, K. N. Kudin, V. N. Staroverov, R. Kobayashi, J. Normand, K. Raghavachari, A. Rendell, J. C. Burant, S. S. Iyengar, J. Tomasi, M. Cossi, N. Rega, J. M. Millam, M. Klene, J. E. Knox, J. B. Cross, V. Bakken, C. Adamo, J. Jaramillo, R. Gomperts, R. E. Stratmann, O. Yazyev, A. J. Austin, R. Cammi, C. Pomelli, J. W. Ochterski, R. L. Martin, K. Morokuma, V. G. Zakrzewski, G. A. Voth, P. Salvador, J. J. Dannenberg, S. Dapprich, A. D. Daniels, Ö. Farkas, J. B. Foresman, J. V. Ortiz, J. Cioslowski, and D. J. Fox, GaUssian 09, Revision E. 01, Gaussian, Inc., Wallingford, CT, 2009, p. 2009.

${ }^{61}$ A. D. Becke, J. Chem. Phys. 98, 5648 (1993).

${ }^{62}$ C. Lee, W. Yang, and R. G. Parr, Phys. Rev. B 37, 785 (1988).

${ }^{63}$ D. S. Banks and C. Fradin, Biophys. J. 89, 2960 (2005).

${ }^{64}$ R. R. Lloyd, J. L. Provis, and J. S. J. Van Deventer, Cem. Concr. Res. 40, 1386 (2010).

${ }^{65}$ T. Kanaya, I. Tsukushi, and K. Kaji, Prog. Theor. Phys. Suppl. 126, 133 (1997).

${ }^{66}$ V. Van Hoang, Phys. B Condens. Matter 400, 278 (2007).

${ }^{67} \mathrm{~J}$. Brus, S. Abbrent, L. Kobera, M. Urbanova, and P. Cuba, Advances in $27 \mathrm{Al}$ MAS NMR Studies of Geopolymers, 1st ed. (Elsevier Ltd., 2016).

${ }^{68}$ K. Krynicki, C. D. Green, and D. W. Sawyer, Faraday Discuss. Chem. Soc. 66, 199 (1978).

${ }^{69}$ P. Demontis, H. Jobic, M. A. Gonzalez, and G. B. Suffritti, J. Phys. Chem. C 113, 12373 (2009).

${ }^{70}$ A. C. T. van Duin, S. Dasgupta, F. Lorant, and W. A. Goddard, J. Phys. Chem. A 105, 9396 (2001). 